\title{
WestVirginiaUniversity
}

THE RESEARCH REPOSITORY @ WVU

Graduate Theses, Dissertations, and Problem Reports

2004

\section{Recycling of plastics derived from end-of-life (EOL) electronic equipment}

\author{
Xiufang Cheng \\ West Virginia University
}

Follow this and additional works at: https://researchrepository.wvu.edu/etd

\section{Recommended Citation}

Cheng, Xiufang, "Recycling of plastics derived from end-of-life (EOL) electronic equipment" (2004). Graduate Theses, Dissertations, and Problem Reports. 1531.

https://researchrepository.wvu.edu/etd/1531

This Thesis is protected by copyright and/or related rights. It has been brought to you by the The Research Repository @ WVU with permission from the rights-holder(s). You are free to use this Thesis in any way that is permitted by the copyright and related rights legislation that applies to your use. For other uses you must obtain permission from the rights-holder(s) directly, unless additional rights are indicated by a Creative Commons license in the record and/ or on the work itself. This Thesis has been accepted for inclusion in WVU Graduate Theses, Dissertations, and Problem Reports collection by an authorized administrator of The Research Repository @ WVU. For more information, please contact researchrepository@mail.wvu.edu. 


\title{
Recycling of Plastics
}

\section{Derived from End-of-life (EOL) Electronic Equipment}

\author{
Xiufang Cheng
}

\author{
Thesis Submitted to the \\ College of Engineering and Mineral Resources \\ at West Virginia University \\ in partial fulfillment of the requirements \\ for the degree of \\ Master of Science \\ in \\ Chemical Engineering
}

Dr. Richard Turton

Dr. John W. Zondlo

Mr. Liviu Magean

\section{Department of Chemical Engineering \\ Morgantown, West Virginia \\ 2004}

Keywords: plastics, recycling, FTIR, Polycarbonate, Polystyrene, dissolution 


\section{Abstract \\ Recycling of Plastics \\ Derived from End-of-life (EOL) Electronic Equipment \\ Xiufang Cheng}

This research work focuses on a chemical process to separate mixed plastics from EOL electronic equipment.

The most prominent components of waste plastics, PC (Polycarbonate), PS (Polystyrene) and ABS (Acylonitrile Butadiene Styrene) from obsolete computers are taken to be samples in this work. Qualitative analysis was carried out to identify these samples using FT-IR (Fourier Transform Infrared Spectroscope). Quantitative analysis was performed using Elemental Analyzer to get the calibration curves for PC/PS and PC/ABS. A number of organic solvents were investigated to dissolve the desired samples. A series of separation experiments were carried out with PC/PS, PC/ABS, and PC/PS/ABS mixtures under optimized conditions. Overall mass balances checked for each experiment. Recovery in all experiments in this study is over $95 \%$ by making material balance.

Cyclohexane and acetone were appropriate solvents for PS and ABS respectively. Water and ethanol were used as antisolvents. Purity of over 97\% of recovered PC is observed for all separation experiments. Both PS and ABS are also purified during the separation process. A preliminary economic analysis was carried out and the feasibility of this chemical separation method is checked. 


\section{Acknowledgements}

It is difficult to express my sincere gratitude to my research advisor, Dr. Richard Turton, for giving me this opportunity to study in West Virginia University. His guidance, patience and encouragement during this work have been invaluable to me. It is really a great pleasure to meet and work with such a nice gentlemen like him.

I'm also extremely grateful to Dr. John W. Zondlo for his useful suggestions and comments, for allowing me to use equipments in his lab, and for kindly providing me solvent NMP during this study.

I would like particularly to acknowledge Mr. Liviu Magean for teaching and helping me to use elemental analyzer.

My great appreciation also goes to Dr. Peter G. Stansberry for allowing me to use facilities in his lab. Thanks are extended to Linda Rogers and Bonita Helmick for all the paper work, Jim Hall for technical support. All my friends in Dr. Turton's lab are thanked for their help and support. I would also like to thank US Department of Energy, NETL, Morgantown; US Environmental Protection Agency (US EPA) and Polymer Alliance Zone (PAZ) for their financial support for this project.

Lastly, I would like to thank my family for their unfailing support, love and encouragement. 


\section{Table of Contents}

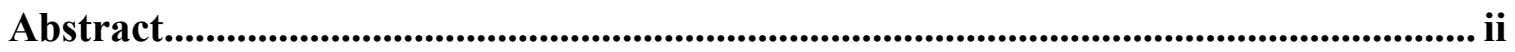

Acknowledgements ...................................................................................................................... iii

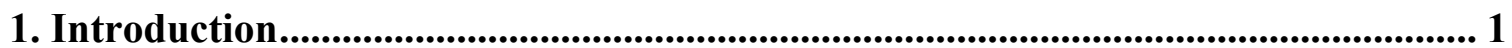

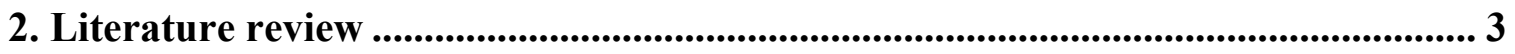

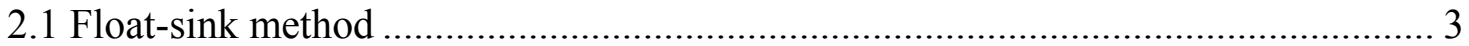

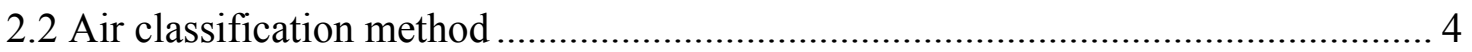

2.3 Froth floatation method................................................................................. 5

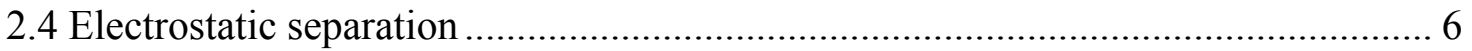

2.5 Selective solvent extraction ...................................................................... 7

3. Experimental Methods ................................................................................................... 10

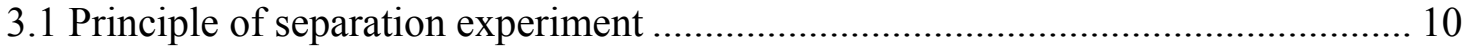

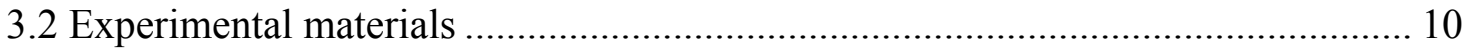

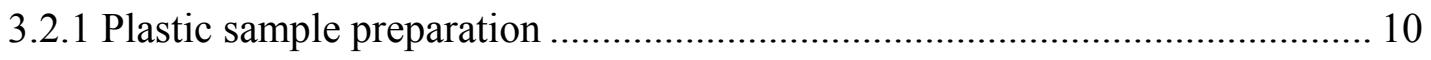

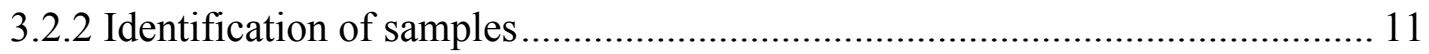

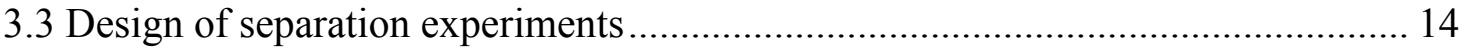

3.4 Experimental apparatus for separation experiments ........................................ 17

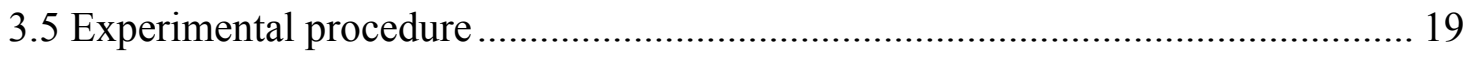

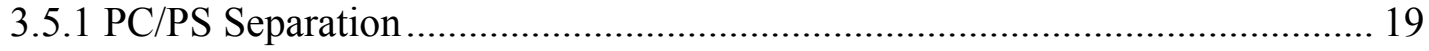

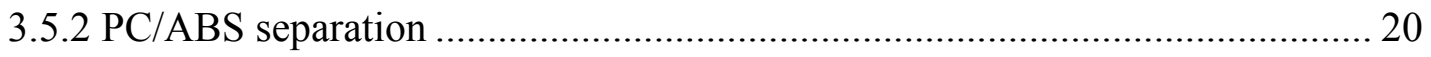

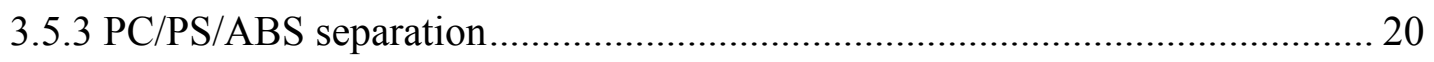

3.5.4 Solvent recycling of separation experiment............................................. 21

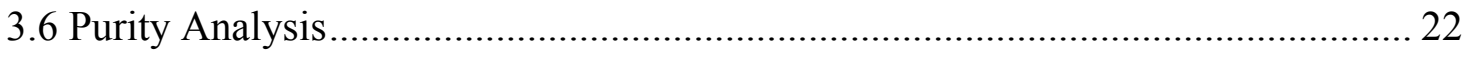

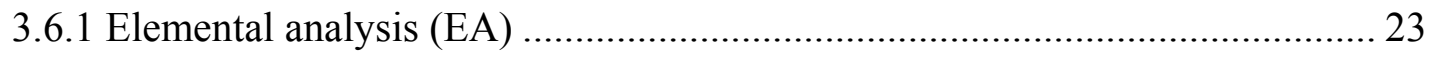

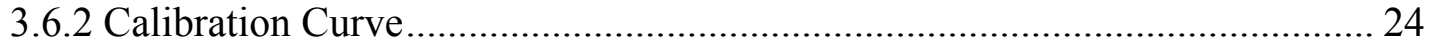

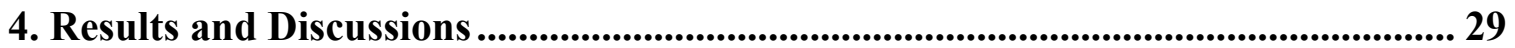

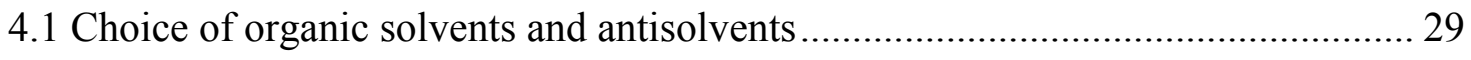

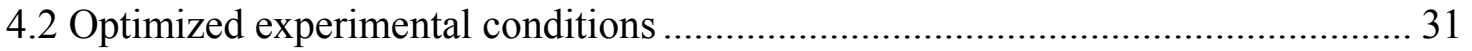

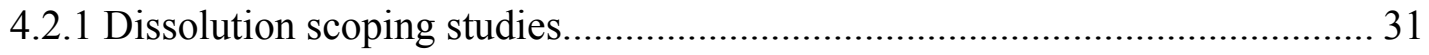

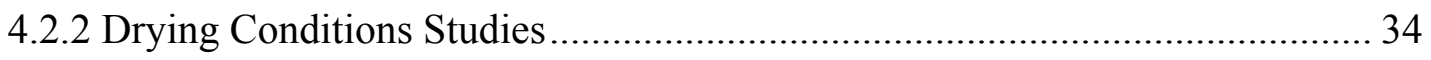




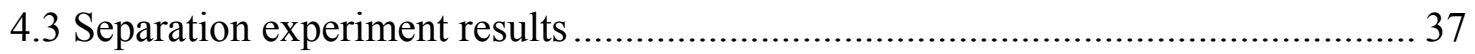

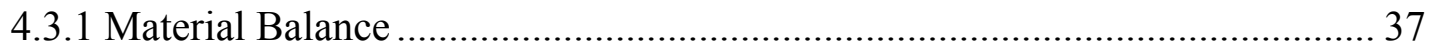

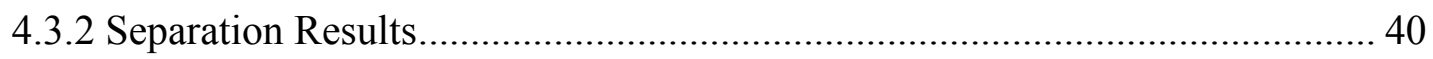

5. Preliminary Economic Analysis ................................................................ 45

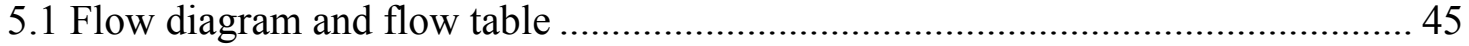

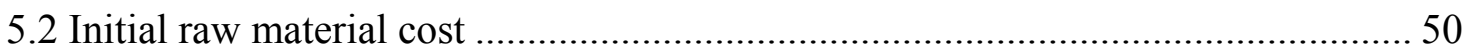

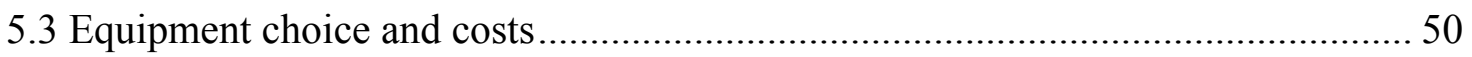

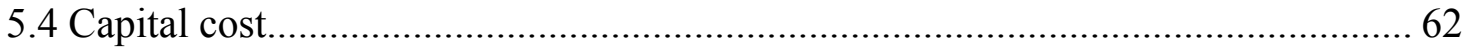

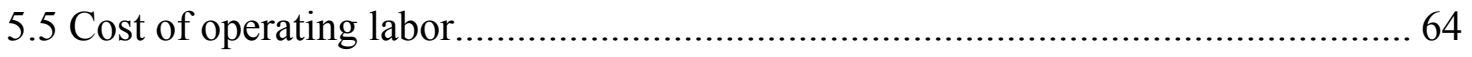

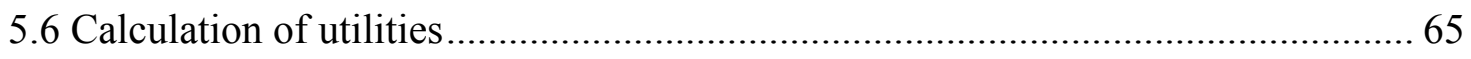

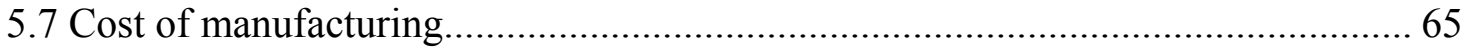

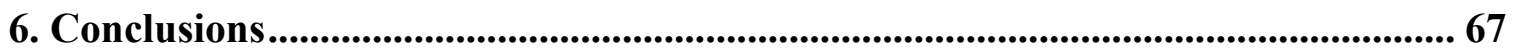

7. Recommendations ..............................................................................................................69 69

References........................................................................................................................................ 71

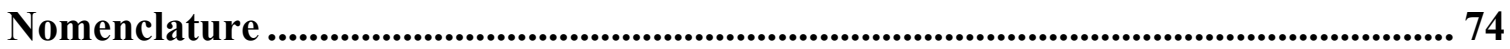




\section{List of Figure}

Figure 3.1 FRITSCH Power Cutting Mill "pulverisette 25" ..................................... 11

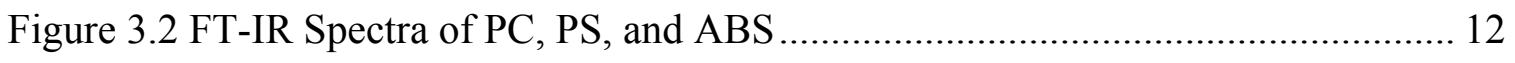

Figure 3.3 PC and PS separation process using selective dissolution method ................ 14

Figure 3.4 PC and ABS separation process using selective dissolution method............. 15

Figure 3.5 PC/PS/ABS separation process using selective dissolution method ............... 16

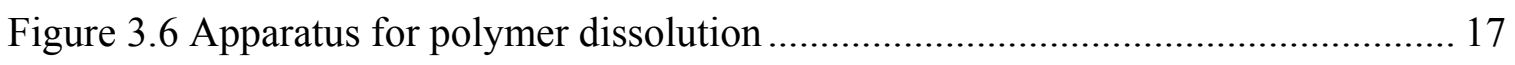

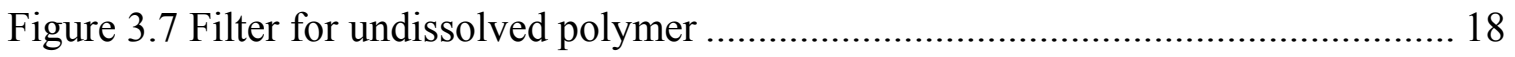

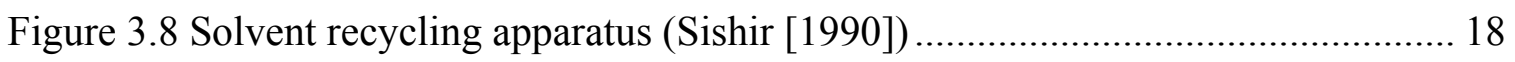

Figure 3.9 The liquid-vapor equilibrium diagram of acetone-water system .................. 22

Figure 3.10 Molecular structures of PC, PS and ABS ............................................... 23

Figure 3.11 Basic experimental steps needed to obtain the calibration curve ................. 25

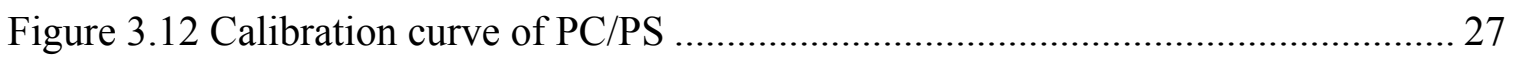

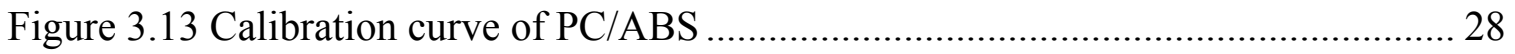

Figure 4.1 Vapor pressure relationship as a function of temperature for three different

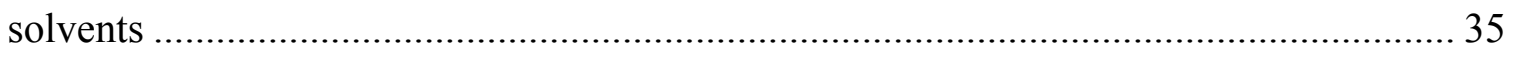

Figure 4.2 The Relationship of PC Weight with Drying Time.................................... 36

Figure 4.3 The Relationship of PS Weight with Drying Time .................................. 36

Figure 4.4 The Relationship of PC Weight with Drying Time.................................... 36

Figure 4.5 The Relationship of ABS Weight with Drying Time .................................. 37

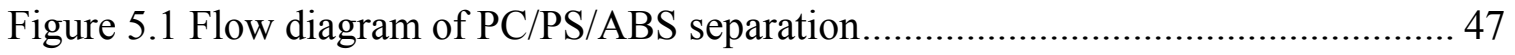

Figure 5.2 The schematic diagram of distillation tower .......................................... 53

Figure 5.3 Equilibrium stage requirements for the separation of water and acetone ....... 55

Figure 5.4 Values of $\mathrm{K}_{\mathrm{v}}$ at flooding conditions for sieve plates (McCabe et al. [1993]).. 57 


\section{List of Table}

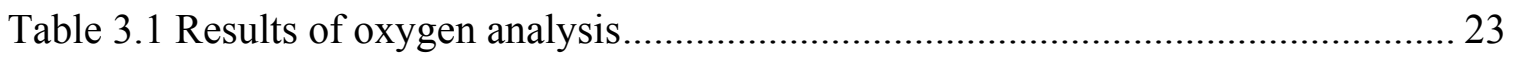

Table 3.2 Material Balance of calibration curve experiment.......................................... 26

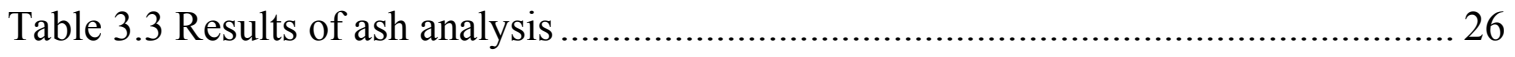

Table 4.1 The solubility parameter of solvents and polymers (Barton [1985])…........... 29

Table 4.2 Solubility of polymers at room temperature .................................................... 30

Table 4.3 Experimental conditions for dissolution of PS in cyclohexane ........................ 32

Table 4.4 Solubility of PS at different temperatures.................................................. 32

Table 4.5 Experimental conditions for dissolution of ABS in Acetone .......................... 32

Table 4.6 Dissolution conditions for separation experiments......................................... 33

Table 4.7 Experimental data for vapor pressure of organic solvents............................... 34

Table 4.8 Material balances of separation experiments with PC/PS $=9 / 1 \ldots \ldots \ldots \ldots \ldots \ldots \ldots \ldots . . . . .38$

Table 4.9 Oxygen balances of separation experiments with $\mathrm{PC} / \mathrm{PS}=9 / 1$........................ 38

Table 4.10 Material balances of separation experiment with $\mathrm{PC} / \mathrm{ABS}=9 / 1$.................... 39

Table 4.11 Oxygen balances of separation experiment with $\mathrm{PC} / \mathrm{ABS}=9 / 1 \ldots \ldots \ldots \ldots \ldots \ldots \ldots \ldots . . .39$

Table 4.12 Material Balances of separation experiment with $\mathrm{PC} / \mathrm{PS} / \mathrm{ABS}=9 / 0.5 / 0.5 \ldots . . .39$

Table 4.13 Oxygen Balances of separation experiment with PC/PS/ABS=9/0.5/0.5 ...... 40

Table 4.14 Oxygen percentages of original samples ...................................................... 41

Table 4.15 Oxygen analysis results of recycled PC and PS .......................................... 41

Table 4.16 Calculated purity of recycled polymer....................................................... 42

Table 4.17 Oxygen analysis results and calculated purities of PC and ABS................... 43

Table 4.18 Oxygen analysis results and calculated purities of PC and ABS.................... 44

Table 5.1 Flow table for PC/PS/ABS separation process ................................................ 48

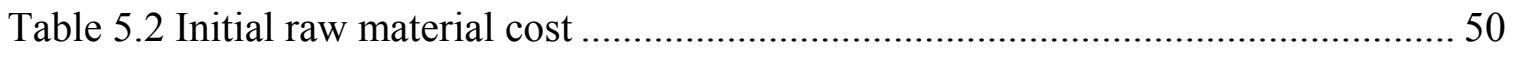

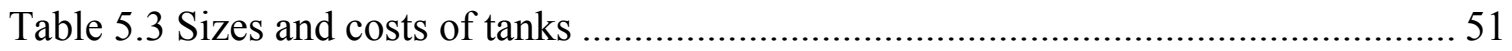

Table 5.4 Size and costs of vibrating screen separator .................................................... 52

Table 5.5 Size and costs of Vacuum tray dryers........................................................... 53

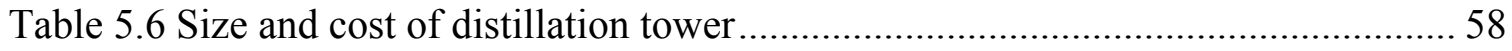

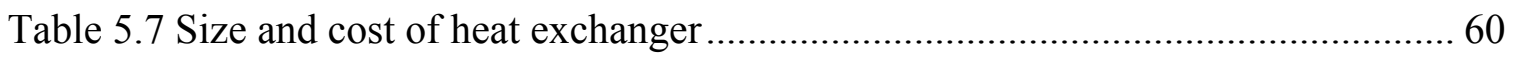

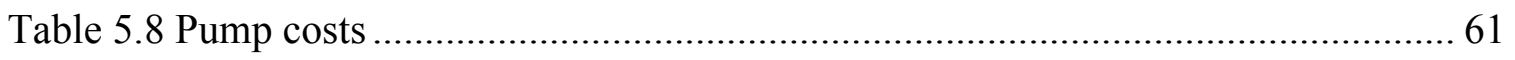




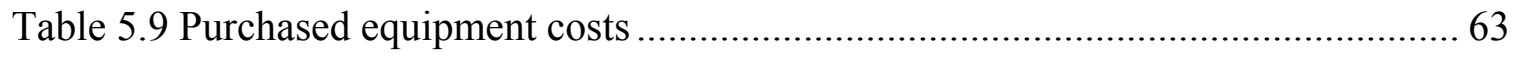

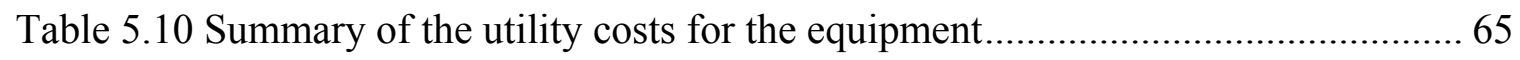

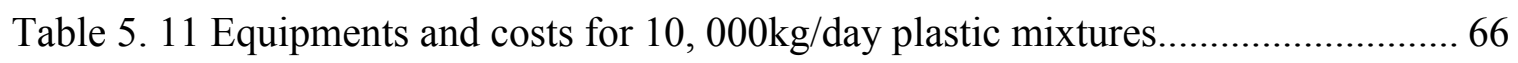




\section{Introduction}

The use and manufacture of electronic equipment has developed very quickly and continues to spread everywhere in modern life. A recent study performed by Biancaniello et al. [2003] shows that about 17 percent of materials from End-of-Life (EOL) electronics are plastics. So this development has lead to a significant increase in waste plastics derived from EOL electronic equipment, but the amounts of recycled plastics are limited. Plastics containing equipment are an environmental problem due to many hazardous materials housed in the equipment. Therefore, land filling of this equipment could lead to serious contamination problems and also waste storage is limited. Microorganisms can never decompose many of the plastics. Moreover, if such plastics are burnt, toxic gases, which may also corrode the furnace, are often generated and must be removed prior to being released to the atmosphere. Therefore, if these plastics can be recovered successfully, then incineration and the subsequent generation of toxic gases can be reduced, the amount of waste going to the landfill can be reduced, and finally the space for land filling will be saved.

Obviously, from the standpoint of environmental protection and economic reasons, there is a great need to recover and reuse the plastic waste by means of effective and economic methods of separation and recovery. Many researchers have attempted to deal with these problems through various methods of recycling plastics. Although existing technologies are effective in separating certain plastics, they are not cost effective, especially when dealing with plastics that have overlapping specific gravities (Pomykala et al. [2003]). 
The purpose of this study is to investigate the possibility of developing a cost effective technology to separate and recover individual plastics at high purities and yields from mixed EOL electronics. EOL computer plastics are selected to be representative samples of EOL electronics because the proliferation of computers in recent years makes computer plastics a large portion of waste plastics. This study will focus on separation and recycling of PS (polystyrene), ABS (Acrylonitrile Butadiene Styrene), and PC (polycarbonate), since these are the main components of computer scrap. Also, from a report by MBA polymers [1999], PS and ABS represent major components of waste plastics in EOL Electronic equipment. 


\section{Literature review}

By the 1990s, plastic recycling became common in the United States. Subsequently, encouraged and supported by the plastic industry, many attempts have been made to separate and recycle waste plastics, and numerous reports and papers are published on the most effective and efficient ways to recover plastics. Initially, plastic separation and recycling technology can be traced to manual operation in which plastics were separated via hand sorting. Although higher purity plastics can be obtained, this technology cannot be widely used in the U.S. because of expensive labor costs and low productivity. As mechanical separation technology developed, manual separation was gradually replaced, and more separation technologies based on mechanical operations were suggested. According to Hendrix and Massey et al. [1997], the existing separation technologies are classified into the following groups.

\subsection{Float-sink method}

The float-sink method involves placing the mixed waste to be separated into a vessel and using liquids of varying density to separate plastics with different densities. The liquid media that have been widely used include water, water alcohol mixtures, and aqueous salt solutions, etc. (Leidner [1981]). Examples of this technology using supercritical fluids have also been given by Super et al [1993]. Mixtures of $\mathrm{HDPE} / \mathrm{LDPE} / \mathrm{PP}$ and PVC/PET were separated by using near-critical $\mathrm{CO}_{2}$ and nearcritical mixtures of $\mathrm{CO}_{2}$ and $\mathrm{SF}_{6}$ fluids as variable-density separation media. The purity of separated homopolymers ranged from $77 \%-100 \%$ by weight, with most runs yielding $96 \%-100 \%$ purity. The advantage of this method is that near-critical fluids can attain densities that span the density range of many recyclable thermoplastics at room 
temperature. Furthermore, there is no significant swelling or dissolution of many plastics, and the particles dry immediately after reducing the pressure to atmospheric conditions. In addition, the low viscosity of these fluids greatly enhances the settling velocities of the particles versus those in conventional liquids. Another distinct advantage of supercritical fluids is that the surface tensions of supercritical fluids are extremely low; hence, they wet all materials in a float-sink separation scheme. However, a major disadvantage of this method is that it takes a long time for flakes to settle, and supercritical conditions are difficult to achieve and require expensive equipment and high utility costs.

\subsection{Air classification method}

The air classification method was originally used in industries such as agriculture, where the air classifier was used to separate, for example, wheat from chaff (Walas [1988]). Usually, in the Plastic Industry, it is used to remove fluff (foam and paper) from mixed plastics.

This simple method is similar to the float sink method but uses air as the separating agent. This method investigated by Stessel and Pelz [1994] uses a steady, rising current of air to separate lighter particles from heavier ones, separation occurs by aerodynamic lightness, not density. Air classification has the advantage of being a dry operation. However, the separation is affected by both density and particle size, because a less dense, larger particle is equivalent to a smaller, denser one. So a clear separation can never be achieved by steady airflow, especially for plastic mixtures with similar densities, such as PET and PVC; another disadvantage is that using this method will leave residual dirt and odor on the plastics. 


\subsection{Froth floatation method}

According to Walas [1988], the main application of froth floatation is the separation of valuable minerals from gangue. And the chief non-mineral application of froth floatation is the removal of oil, grease or fibrous materials from wastewater of refineries or food processing plants. In another application, particles of plastics in waste streams are chopped to diameters of $5 \mathrm{~mm}$ or less, passed through floatation cells containing proprietary surfactants and removed as air froth.

When using the froth floatation method, the hydrophobic surface characteristics of plastic materials are used to separate polymer mixtures. A surfactant is used to make one material more hydrophilic, and air bubbles are introduced and attach themselves to the hydrophobic material causing it to float in a liquid in which the other plastic sinks (Hwang [1995]). A disadvantage of this method is the relatively high capital cost and lack of a sharp separation.

Experiments using a froth-floatation cell were carried out by Vasudevan [2003] at West Virginia University. Methyl isobutyl carbinol (MIBC) was used as the frother, while oleic acid and n-dodecylamine hydrochloride were used as the two surfactants. The main focus of the work was on the separation of PS and ABS, and it was reported that a 3-stage setup with recycle was the optional for obtaining high purity and yield for both PS and ABS.

The above three methods are termed density separations because the difference in density is used to separate plastics. The limitation of density separation is that many polymers have similar density such as PVC (Polyvinylchloride) and PET (Polyethylene terephthalate), PS and ABS, etc. The difficulties encountered with density separation 
include low-efficiency separation (because of the entanglement of the materials) and the cost of additional drying when water is used as the separation medium. The presence of different amounts of dirt on the plastics complicates the process (Jody and Daniels [1994]), because the separation of same density plastics is very sensitive to surface contamination.

\subsection{Electrostatic separation}

Electrostatic or triboelectric separation works on a very simple principle; namely when different materials are rubbed together, they obtain different surface charges. This surface charge difference can be used to separate dissimilar materials from each other in an electrical field. An example of this technology was provided by Xiao et al. [1999]. In this paper, a triboelectric separator was evaluated at MBA Polymers, Inc. to separate commingled plastics from EOL durables. The separation of ABS and HIPS derived from electronic shredder residue (ESR), and the separation of PC and PVC from water bottles was tested. The results showed that the Plas-Sep device can separate ABS from HIPS, and that the separation of water bottle PC and PVC was very promising. But the feasibility of separating more complicated feedstock has not been checked. Sharp separation between two polymers is possible but operating costs tend to be high due to material handling and supervision issues. In addition, operating costs for turboelectric separators are sensitive to throughput, yield, and the purity requirements of the products. 


\subsection{Selective solvent extraction}

When using selective solvent extraction, a solvent can be used at ambient pressure to dissolve all the plastic of interest and then mixed plastics can be separated by sequentially using different solvents.

In U.S. Patent No. 5,594,035 Walsh [1997] describes a process for the reclamation of polystyrene and other styrene containing polymers. Polystyrene was dissolved in NMP (N-Methyl Pyrrolidone) and then precipitated out of solution by adding water. The particles of polymer that precipitate at the bottom of the container or float to the surface of the water can be collected and dried. Using a solvent that is safe for the environment, the reclamation process involved dissolving styrene polymer scrap material into a totally water soluble solvent, such as NMP to form a water-soluble solvent/styrene polymer solution. This water-soluble solvent /styrene solution is then added to water. The styrene polymer, upon contact with the water, precipitates out and floats to the surface.

Mizumoto and Hasegawa [1977] disclose a method for treating polystyrenic polymer with an organic solvent such as benzene, toluene or xylene in U.S.Patent No. $4,031,039$. This process takes advantage of the dissimilar solubility of different plastics in different organic solvents. It was experimentally confirmed that organic solvents so chosen have the functions to both fractionate and purify the polymers.

In U.S. Patent No. 4,517,312, Kumasaka et al. [1985] describe a process for regenerating a resin. First a waste resin was dissolved in an organic solvent, and then water was added to the resin solution. Water is immiscible with the solvent, and the resin scarcely dissolves in water. The specific gravity of water was lower than that of solvent 
but greater than the resin; thereby the resin was separated from a mixture of resin solution and water, and subsequently recovered. The solvent was selected from the group consisting of methylene chloride, trichloroethylene, and carbon tetrachloride, and the resin was polystyrene. Since the solvents chosen are all toxic, and not readily biodegradable, water-pollution and air-pollution problems exist for such a process.

The advantage of this method is that a resin can be regenerated while allowing recycling of the solvent by an extremely simple method, and without requiring largescale equipment or high energy.

In U.S.Patent No. 4,196,105, Kubat et al. [1980] show a recovery process for polystyrene using liquid sulfur dioxide, wherein the polystyrene is dissolved and forms two phases, the polystyrene is recovered from the upper polystyrene-containing phase by boiling off the sulfur dioxide.

The upper phase contains the polystyrene and a lower phase contains the sulfur dioxide solvent, which is practically free from polystyrene and which can be reused in the process.

In U.S.Patent No. 5,300,267, Moore [1994] discloses a process and apparatus to reclaim polystyrene-type polymer. The polymer was dissolved in a solvent in a dissolving tank. A recovery tank was used to receive the solution from the dissolving section. A separator unit was used to separate the dissolved polymer material in solid form from the solvent. A solid material processing unit was used to remove the reclaimed polystyrene-type polymer material from the separator unit and a fluid separator/recovery unit was used to remove moisture from the separator unit and to separate and recover the solvent from water. 
Despite all of these approaches, a commercial process based on any of these technologies could not be found. However, laboratory work in these patents shows the potential to separate polymers by solvent dissolution, filtration and precipitation steps. The advantages of these processes, which use solvents, are:

1. Fillers and pigments may be removed by filtration.

2. Plastics that have similar density, such as ABS and PS can be separated.

3. Typical contaminants do not upset the systems.

A disadvantage of these processes is that if fractionation of solvents is involved then large-scale equipment is needed and high energy is required. 


\section{Experimental Methods}

The primary purpose of this project is to separate and recycle plastic mixtures. The first step was to collect plastic samples. In this project, obsolete computers are dismantled by hand and plastic components are collected and identified. Representative samples are taken and analyzed in terms of physical and chemical properties. It is further desired that appropriate solvents can be found to separate binary or ternary mixtures of plastics.

\subsection{Principle of separation experiment}

As Vestolit and Solvay [2002] described, it is well known that commonly used plastics can be dissolved in suitable solvents, and the different solubility behavior of polymers can be used to separate mixed plastics. In this work, a solvent in which one polymer can be dissolved but another polymer does not dissolve will be chosen. Then the mixed plastics will be dissolved in organic solvents at ambient pressure and elevated temperature. Finally, the desired plastics will be separated by selective dissolution, filtration, and precipitation (by the addition of "anti-solvents" or by evaporating the solvents).

\subsection{Experimental materials}

\subsubsection{Plastic sample preparation}

All kinds of electronic equipment can be used as the source of plastic waste, such as refrigerators, television sets, copy and fax machines, printers, computers, etc. In this project, obsolete computers were selected as the representative source of plastic waste. They were dismantled by hand, and the plastics they contained were collected and then 
were shredded into scrap polymer using a FRITSCH Power Cutting Mill "pulverisette 25" shredder (Figure 3.1). All waste plastics were shredded and granulated to approximately $4 \mathrm{~mm}$ in size.

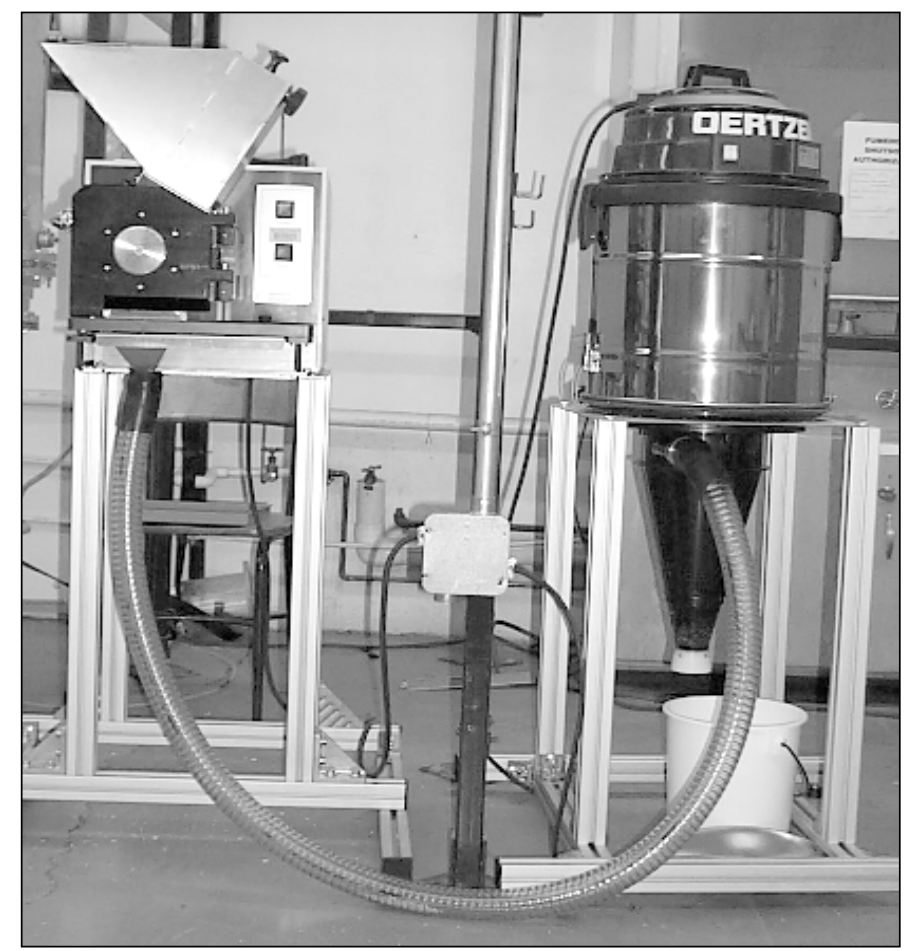

Figure 3.1 FRITSCH Power Cutting Mill "pulverisette 25"

\subsubsection{Identification of samples}

The identification of plastics prior to recycling is a crucial step in the plastic recycling industry. The purpose of identification is to determine what plastic resins are present in computer scrap. Because different plastics have distinguishable light absorption spectra, electromagnetic absorption and reflectance measurements can be used to sort them. Reflected spectra are detected and analyzed to determine the type of plastic.

Representative samples collected from computer scrap were taken from each piece and identified using a Perkin Elmer FT-IR (Fourier Transform Infrared Spectroscope). It was shown that the three most prominent types of plastics in computer 
waste are ABS, PS and PC. Therefore this work focuses on the separations of these three polymers. FT-IR spectra for ABS, PS and PC are shown in Figure 3.2.
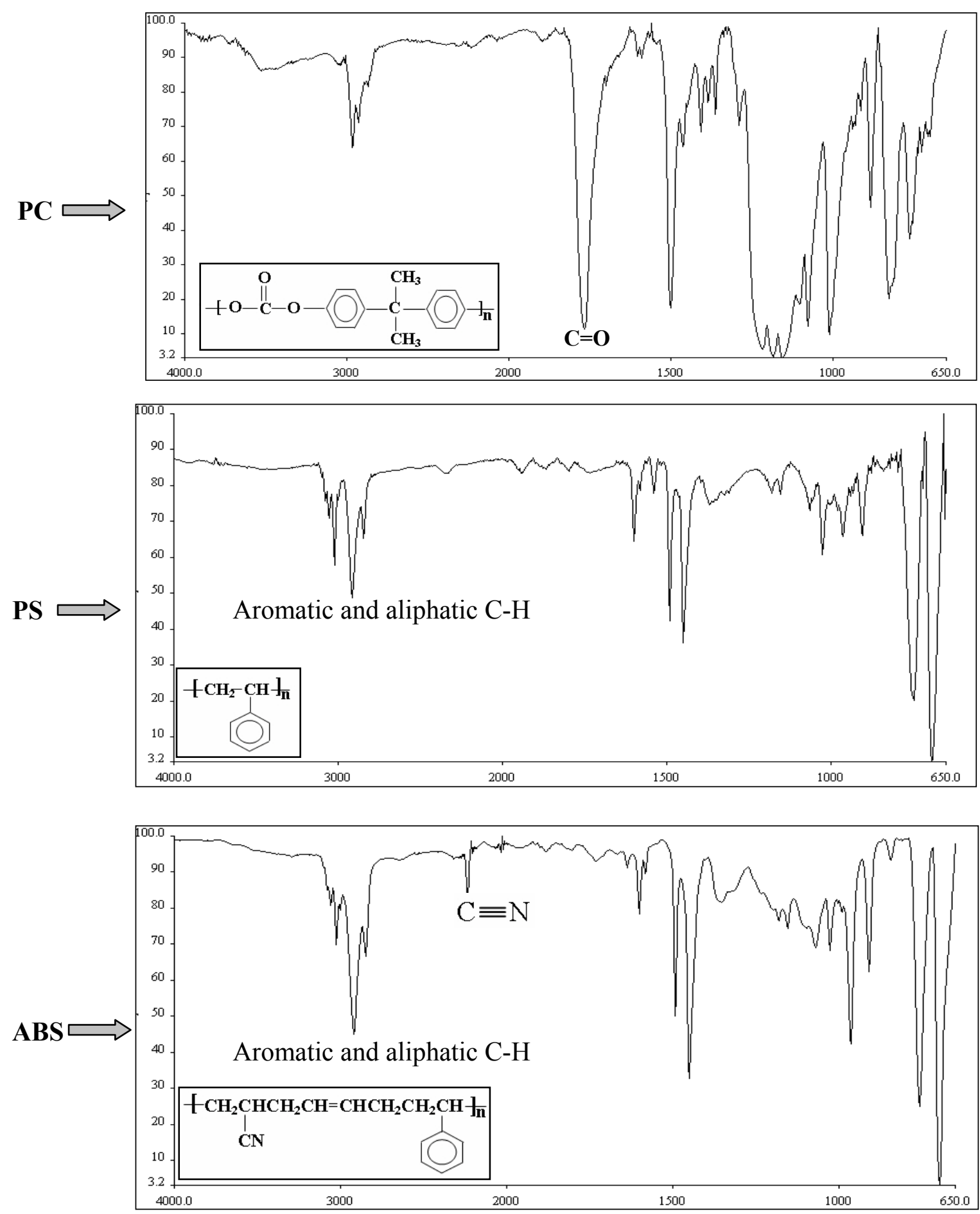

Figure 3.2 FT-IR Spectra of PC, PS, and ABS 
In Figure 3.2, spectra are presented with wavelength as the $\mathrm{X}$-axis. The region $4000-1500 \mathrm{~cm}^{-1}$ in the $\mathrm{x}$-axis is usually a functional group region and peaks in this region are characteristic of specific kinds of bonds and, therefore, can be used to identify whether a specific functional group is present. As can be seen, a carbonyl group $(\mathrm{C}=\mathrm{O})$ for PC appears at around $1730 \mathrm{~cm}^{-1}$; a $C \equiv N$ bond is a characteristic functional group of ABS and appears at around $2300 \mathrm{~cm}^{-1}$. Also, benzene rings show "overtones" in the $1500-1700 \mathrm{~cm}^{-1}$ region. By comparing the PS and ABS spectra, it was found that these two spectra are almost the same except for the absence of the $C \equiv N$ bond in the PS spectrum.

Based on these functional groups and "fingerprints" of these polymers, software in the FT-IR has been used to compare measured spectra against libraries of reference spectra, and results of matches were reported automatically.

It is clear that FT-IR is a powerful tool for qualitative identification of chemical bonds in a molecule. However, efforts at quantitative analysis using FT-IR proved to be particularly difficult. The peak height and peak area of the functional groups in polymers were both calculated to obtain a calibration curve, so that it could be used to predict the composition of plastic mixtures. Such efforts failed because of the poor reproducibility and variability in the calculated data. Therefore, elemental analysis was recommended because of the very good repeatability and linearity of the experimental data. It is used to determine the percent composition of each element present in an organic chemical compound. This technique will be described later in section 3.6. 


\subsection{Design of separation experiments}

Separations of two binary mixtures of PC/PS and PC/ABS, and a ternary mixture of PC/PS/ABS were investigated. Solvents used were cyclohexane and acetone. Detailed information on the choice of solvent will be later described in section 4.1. The design of these separations is illustrated in the following sections.

- Separation of PC/PS

Figure 3.3 shows the basic steps required for the separation of PC from PS. As illustrated in Figure 3.3, when the mixture of PC/PS is added to cyclohexane, only PS is dissolved. Therefore PC can be filtered out. Adding ethanol into the PS/cyclohexane solution causes PS to be precipitated out immediately. The PS is then filtered and dried, and cyclohexane and ethanol can be recycled and reused.

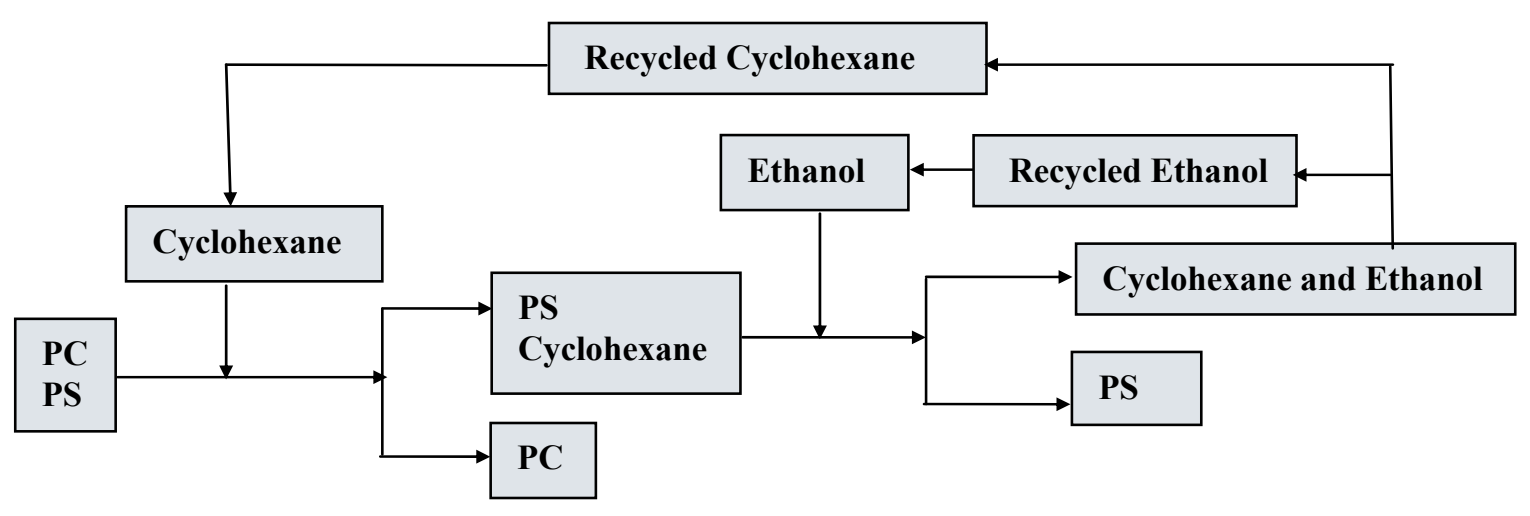

Figure 3.3 PC and PS separation process using selective dissolution method 
- Separation of $P C / A B S$

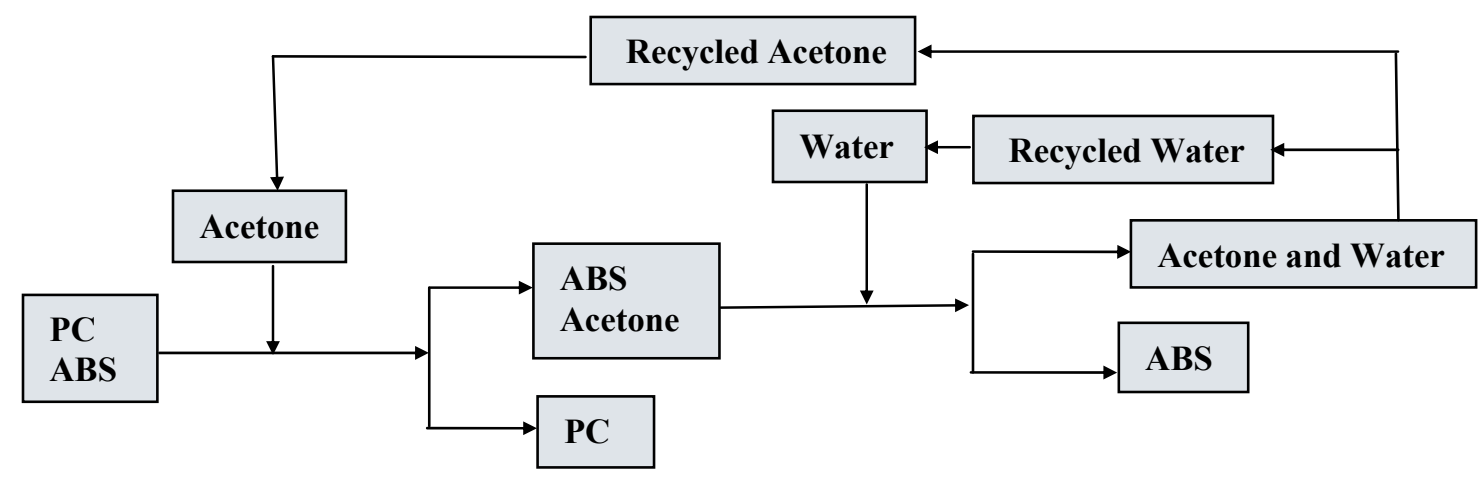

Figure 3.4 PC and ABS separation process using selective dissolution method

Figure 3.4 shows the basic steps for the separation of PC and ABS. As shown in Figure 3.4, when the PC/ABS mixture is added to acetone, only ABS is dissolved. Therefore $\mathrm{PC}$ can be filtered out and then water is added to the ABS/acetone solution, ABS precipitates out immediately and is dried subsequently in a vacuum oven. Acetone and water can be separated by normal distillation and reused.

- Separation of $P C / P S / A B S$

Figure 3.5 demonstrates the basic steps for the separation of a ternary mixture of $\mathrm{PC} / \mathrm{PS} / \mathrm{ABS}$.

The separation process for PC/PS/ABS mixture is simply a combination of the two previous separations. Initially, it was expected that the ternary mixture could be added into a mixture of cyclohexane and acetone. However it was noticed that although cyclohexane and acetone are miscible, cyclohexane is a good antisolvent for ABS in acetone, which means that ABS will not dissolve in the mixture of cyclohexane and acetone. Therefore the PC/PS/ABS mixture cannot be added to the mixture of cyclohexane and acetone. Consequently, the separation of these three plastics must be 
carried out by removing one component first. Theoretically, either step of removing PS or ABS can be the first step, but it was decided that acetone should be used first, because ABS can be dissolved in acetone very easily at room temperature, while PS has to be dissolved in cyclohexane at the normal boiling point of cyclohexane. By removing ABS first, the whole process is simpler, and the energy to heat the mixture of polymers is saved because the amount of the polymer mixture is reduced since ABS has already been removed. Another reason is that the boiling point of acetone is $56.5^{\circ} \mathrm{C}$, and cyclohexane is $80.7^{\circ} \mathrm{C}$. So before cyclohexane was heated to its boiling point, part of the acetone can be evaporated, which will result in significant separation of the solvents.

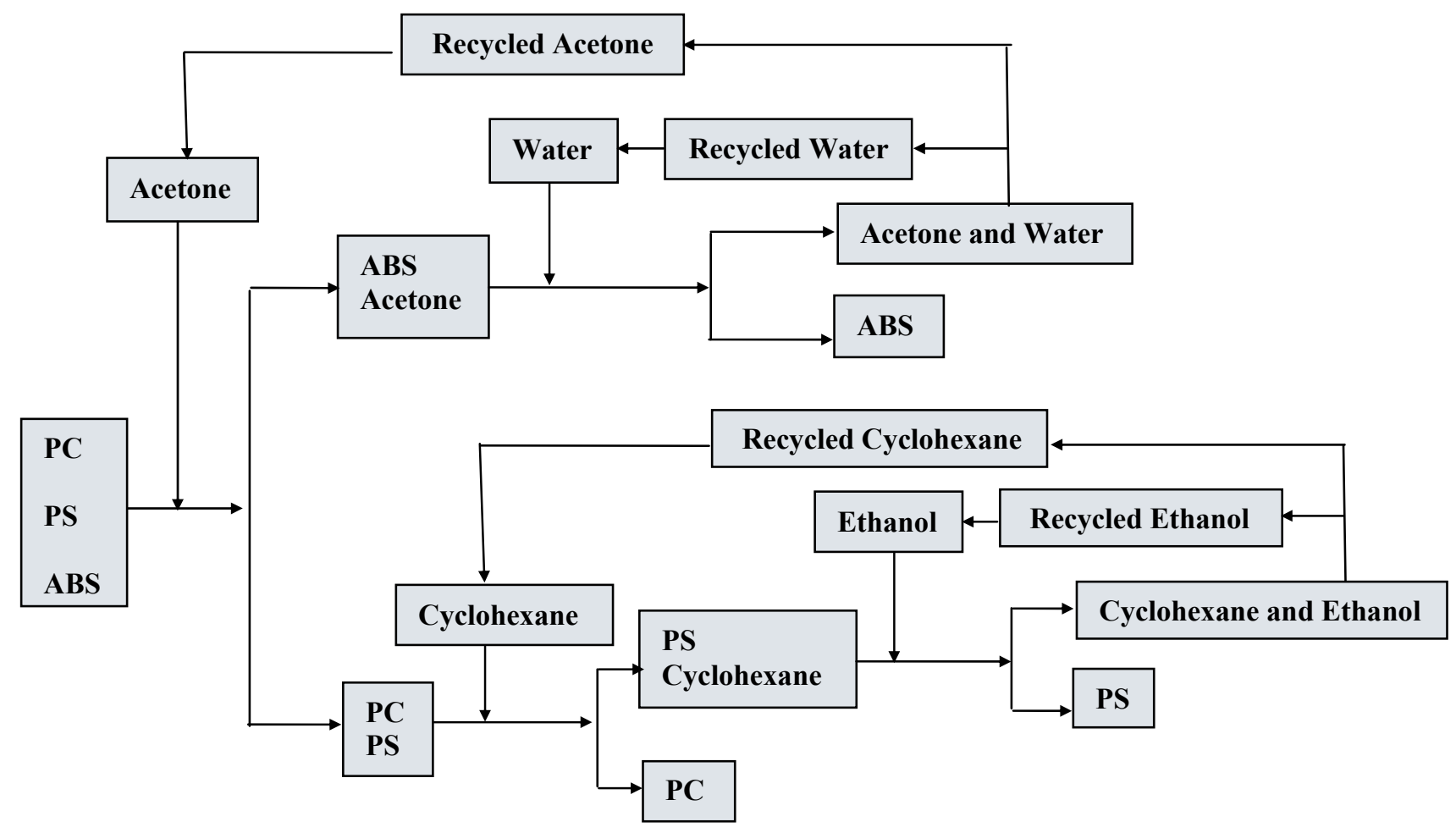

Figure 3.5 PC/PS/ABS separation process using selective dissolution method

Therefore, this separation experiment was carried out by first dissolving ABS in acetone, and then the precipitated mixture of PC/PS was treated using cyclohexane to remove PS from the mixture. Finally, a pure stream of PC was obtained. 


\subsection{Experimental apparatus for separation experiments}

In this study, a lab-scale, solvent-based separation apparatus was constructed to separate the plastics. Figures 3.6 -3.8 illustrate the major components of the experimental apparatus.

As shown in Figure 3.6, the dissolution apparatus is used to dissolve the mixed plastics. A $250-\mathrm{ml}$ round bottom Pyrex flask is placed on a heating mantle, which is connected to a temperature controller (MC239 controller), and attached to a water-cooled reflux condenser, which is used to reduce the loss of solvents.

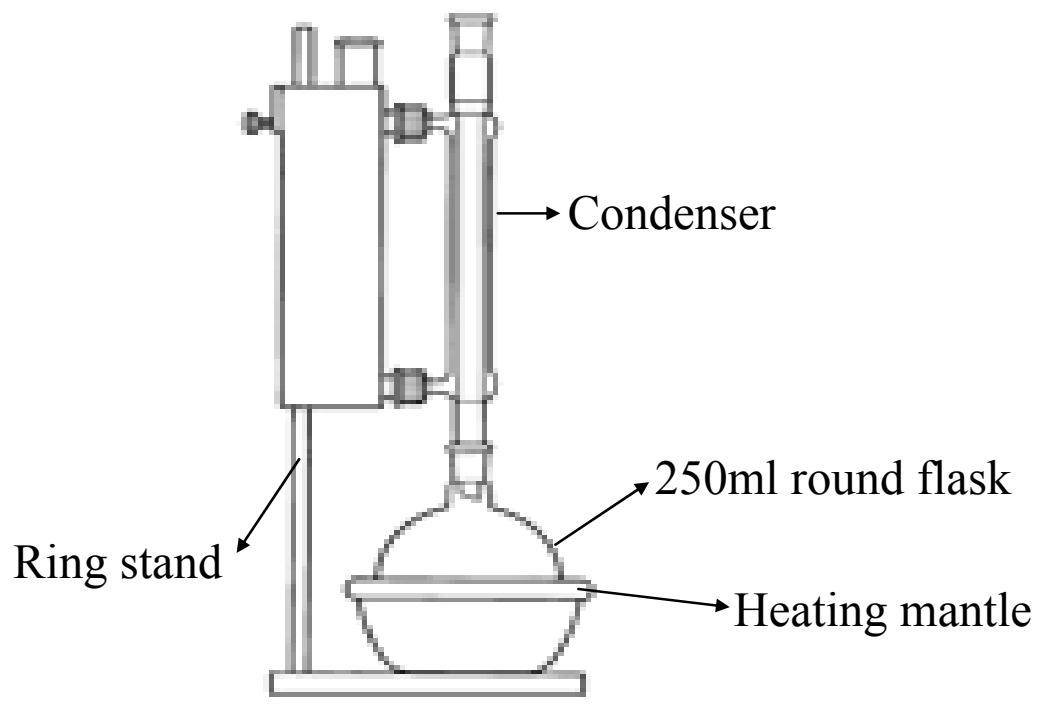

Figure 3.6 Apparatus for polymer dissolution

In Figure 3.7, the filtration apparatus consists of a $1000 \mathrm{ml}$ filtration flask and a funnel. A filter paper is used to fit the funnel. The filtration apparatus is connected to a vacuum pump (Welch vacuum Model 2025). The filtration apparatus shown in Figure 3.7 is used to filter out the inorganic fillers and undissolved polymer from the solvent/polymer solution. Sometimes a centrifuge (Marathon 2500) was also used to 
reduce the filtration time. A handheld strainer was also used for filtration if the sizes of the undissolved polymer particles were large enough.

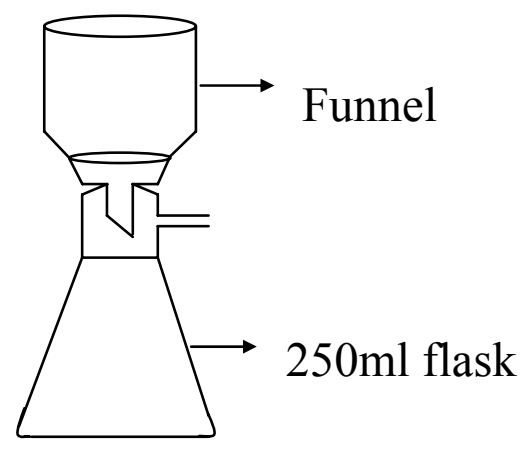

\section{Figure 3.7 Filter for undissolved polymer}

The solvent recycling apparatus includes a $250 \mathrm{ml}$ round bottom flask with a 24/40 joint. This flask is fitted to a rotary evaporator (see Figure 3.8), and the flask is placed in an oil-bath tank. A condenser is connected with the flask to cool down the solvent vapor. A Welch vacuum pump is connected to the system in order to reduce the pressure of the whole system. This equipment is only used in Calibration curve experiments.

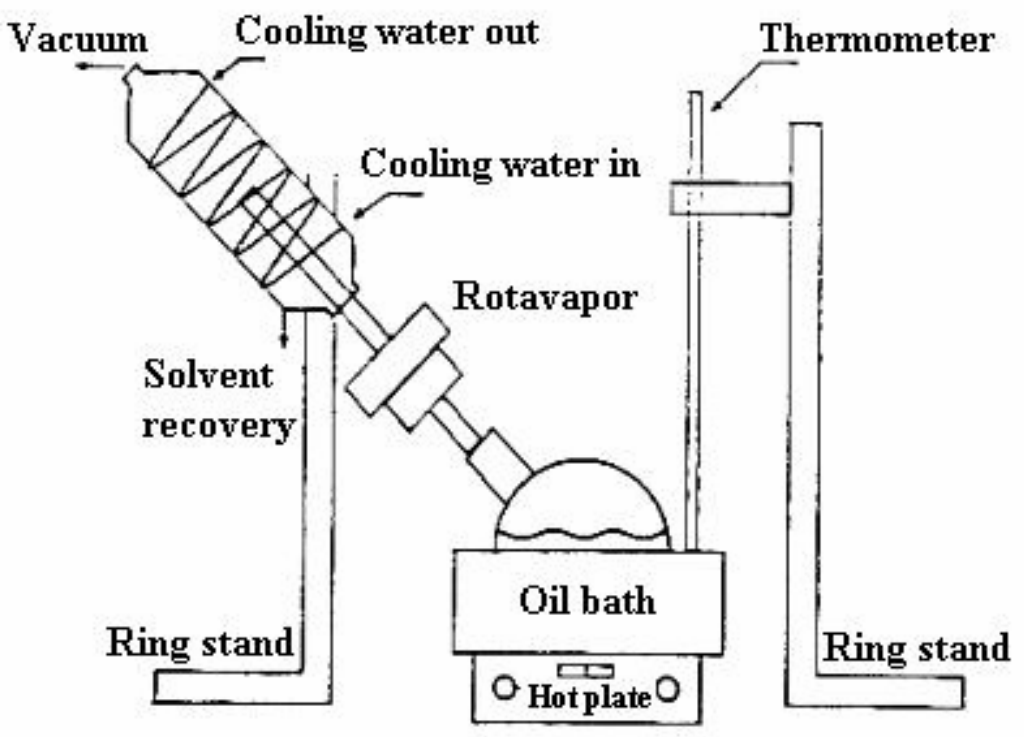

Figure 3.8 Solvent recycling apparatus (Sishir [1990]) 


\subsection{Experimental procedure}

\subsubsection{PC/PS Separation}

Once the plastics were identified, a full-scale analysis was performed. The detailed experimental procedure for the separation of polymer is outlined below:

(1) 9 grams of PC and 1 gram of PS were taken and placed in a 250-ml round bottom Pyrex flask, and 100-ml cyclohexane was added to the flask in Figure 3.6. The mixture was then heated to the normal boiling point of cyclohexane at $80^{\circ} \mathrm{C}$ and maintained at this temperature for 1 hour. The whole dissolution process was carried out in a fume hood.

(2) The undissolved polymer, PC, was filtered using a household strainer, and the undissolved PC was washed with $25 \mathrm{ml}$ ethanol and collected for drying.

(3) The filtrate in the second step was slowly added to $50 \mathrm{ml}$ of ethanol while stirring with a glass rod. PS then precipitated out. This process was carried out in a $1000 \mathrm{ml}$ beaker. The mixture was allowed to stand for a few minutes to ensure complete precipitation.

(4) Precipitated PS was separated from solution by using the filter shown in Figure 3.7 or the centrifuge (Marathon 3200R), and then washed with $25 \mathrm{ml}$ ethanol to remove the trapped solvent before drying.

(5) By following this process, PS and PC were separated; and then the separated PS and PC were dried in a vacuum oven to evaporate the cyclohexane solvent and ethanol antisolvent trapped in the polymer. Because the boiling points of both solvents are not very high, the oven temperature was set to $50^{\circ} \mathrm{C}$ and the pressure set to 200mmHg. 
(6) Finally, the liquid filtrate, which is a mixture of cyclohexane and ethanol, was collected for recovery and reuse.

\subsubsection{PC/ABS separation}

When separating PC and ABS, the same procedure as described in section 3.5.1 was followed. The differences in each step are described below:

(1) 9 grams of PC and 1 gram of ABS were taken and placed in a 250-ml beaker, and 100 $\mathrm{ml}$ acetone was added to the beaker at room temperature and stirred for 30 minutes.

(2) Undissolved PC was washed with $25 \mathrm{ml}$ water and collected for drying.

(3) Dissolved ABS was precipitated out by adding $100 \mathrm{ml}$ water.

(4) ABS was washed with $50 \mathrm{ml}$ water to remove the trapped acetone before drying.

(5) By following this process, ABS and PC were separated; and then the separated ABS and PC were dried in a vacuum oven to evaporate any acetone and water trapped in the polymer.

(6) A liquid filtrate, which is a mixture of acetone and water, was collected for recovery and reuse.

\subsubsection{PC/PS/ABS separation}

As mentioned in the previous section, this ternary mixture separation is a combination of PC/PS and PC/ABS separations. The important steps are described below.

(1) 10-grams of polymer mixture that includes 9 grams of PC, 0.5 gram of PS and 0.5 gram of $\mathrm{ABS}$ were dissolved in $50 \mathrm{ml}$ acetone.

(2) Follow the same procedure described in 3.5.2, the ABS was removed first.

(3) Undissolved PC/PS mixture was added to $50 \mathrm{ml}$ of cyclohexane. 
(4) The same procedure described in 3.5.1 was followed to remove PS. In this way, PC, PS and ABS were separated.

(5) Separated solids were saved for drying and liquids were saved for recycling.

\subsubsection{Solvent recycling of separation experiment}

The liquid filtrate, collected in the separation experiments, was saved for recycling and reuse. The separation experiment actually produces two mixtures of solvents; one is a mixture of cyclohexane and ethanol, and the other is a mixture of acetone and water. Obviously, in a commercial process, it is necessary to recycle and reuse these solvents from an economic viewpoint. Although this part of the work was not performed in the lab, methods that can be used to recycle these solvents were investigated.

\section{- Recycling of Cyclohexane and Ethanol}

Since the boiling points of cyclohexane and ethanol are very close and they form an azeotropic mixture, these two solvents cannot be separated by simple distillation. The suggested method for separating cyclohexane and ethanol is pervaporation. Pervaporation is of special interest when separating liquids with an azeotropic composition and mixtures with close boiling points. It is a membrane based technology in which the liquid feed mixture is brought into contact with one side of the membrane and the permeate, in the form of vapor, is removed by a sweep gas or by creating vacuum on the other side. It was shown by Zhou et al. [1995] that cyclohexane and ethanol could be separated by pervaporation with polypyrrole membranes. 
- Recycling of water and acetone

By checking the physical properties of water and acetone, it was found that acetone is a very volatile liquid. It has a normal boiling point of about $56.5^{\circ} \mathrm{C}$, while the boiling point of water is $100^{\circ} \mathrm{C}$. The difference of boiling point between acetone and water makes it possible to separate and recycle acetone and water by simple distillation. Figure 3.9 shows the vapor-liquid equilibrium diagram of acetone - water.

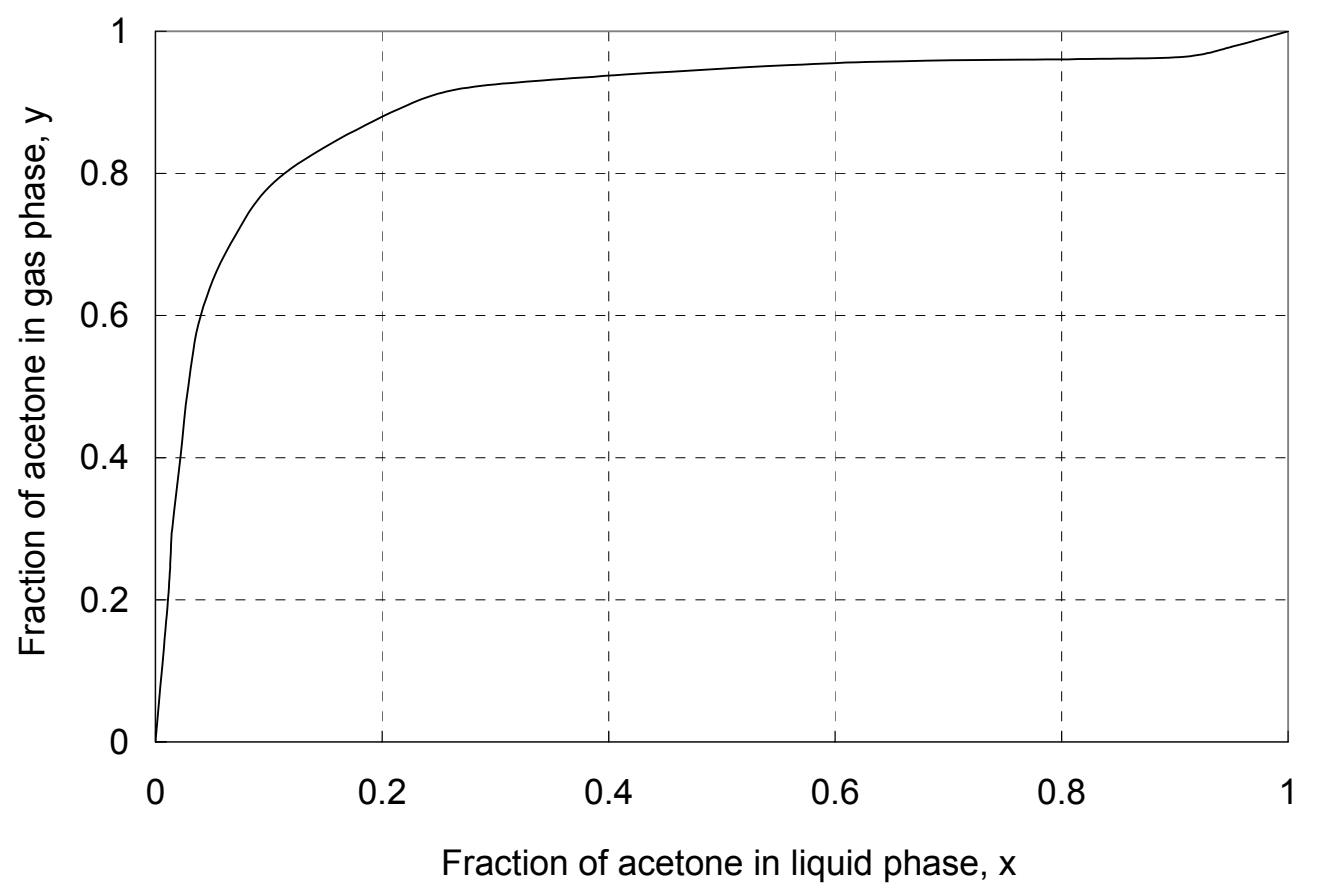

Figure 3.9 The liquid-vapor equilibrium diagram of acetone-water system

\subsection{Purity Analysis}

In separation technologies, purity of the recovered polymer is one measure of the efficiency of the technology. Here, the purity is defined as the weight percentage of an individual material in a mixture. In this work, the purity of polymers can be calculated by using results of elemental analysis, or predicted by calibration curves obtained from elemental analysis of polymer mixtures. 
3.6.1 Elemental analysis (EA)

PC:<smiles>COC(=O)Oc1ccc(C(C)(C)c2ccc(F)cc2)cc1</smiles>

PS:<smiles>CC(C)c1ccccc1</smiles>

ABS:<smiles>CC(C)CC=CCCc1ccccc1</smiles>

Figure 3.10 Molecular structures of PC, PS and ABS

By comparing the molecular structure of PC, PS, and ABS in Figure 3.10, it is clear that an oxygen analysis may be used to determine the relative quantities of PC and ABS or PS in a given mixture because only PC contains oxygen. Therefore, for a mixture of PC and PS or ABS, if the oxygen percent of the mixture can be measured, the ratio of $\mathrm{PC}$ in the mixture can be calculated.

The method of calculating the purity of recovered polymer is as follows. Referring to Table 3.1 and assuming that there is X percent of "pure" PC in the recovered PC from a mixture of PC and PS. Based on the oxygen material balance, the following equation was obtained:

Table 3.1 Results of oxygen analysis

\begin{tabular}{|c|c|c|}
\hline sample & $\mathrm{O}^{\prime}$ in Virgin sample & $\mathrm{O}^{2}$ in recovered sample \\
\hline PC & A & A $^{\prime}$ \\
\hline PS & B & B $^{\prime}$ \\
\hline
\end{tabular}

$$
X A+(1-X) B=A^{\prime}
$$

Hence, the purity of PC is: 


$$
X=\left(A^{\prime}-B\right) /(A-B)
$$

- Experimental Procedure Used in Elemental Analysis

Elemental analysis was performed with a Thermo Quest Flash 1112 Elemental analyzer, which is manufactured by Thermo Electron Corporation. After drying, the recovered polymer is granulated into fine powder by using a mortar and pestle. About $2.5 \mathrm{mg}$ of fine powder is taken as a sample and introduced into a silver capsule and sealed, the sealed capsule is loaded into an auto-sampler, which allows the sample to be dropped into a combustion chamber made of nickel coated carbon, which is maintained at approx. $1060^{\circ} \mathrm{C}$. The pure oxygen in the sample combines with carbon to form $\mathrm{CO}$ that is then chromatographically separated from other combustion products. The analyzed gas is available for further quantitative analysis. By following this procedure, the oxygen percent of each polymer mixture was obtained.

\subsubsection{Calibration Curve}

A calibration curve is another way to predict the purity of polymers. The advantage of using a calibration curve is that errors from multiple experiments may be averaged. Samples with different ratios of PC/PS, or PC/ABS were dissolved in solvents to get homogeneous mixtures, and the oxygen percentage in the mixture was analyzed by the elemental analyzer. Finally, a calibration curve that relates the relationship between oxygen percent and ratios of PC/PS, or PC/ABS was obtained. If the oxygen percentage of recovered polymer is measured, the purity of the polymer may be estimated from the calibration curve. 
- Procedure for calibration curve experiments

Figure 3.11 shows the basic steps needed to obtain a calibration curve.

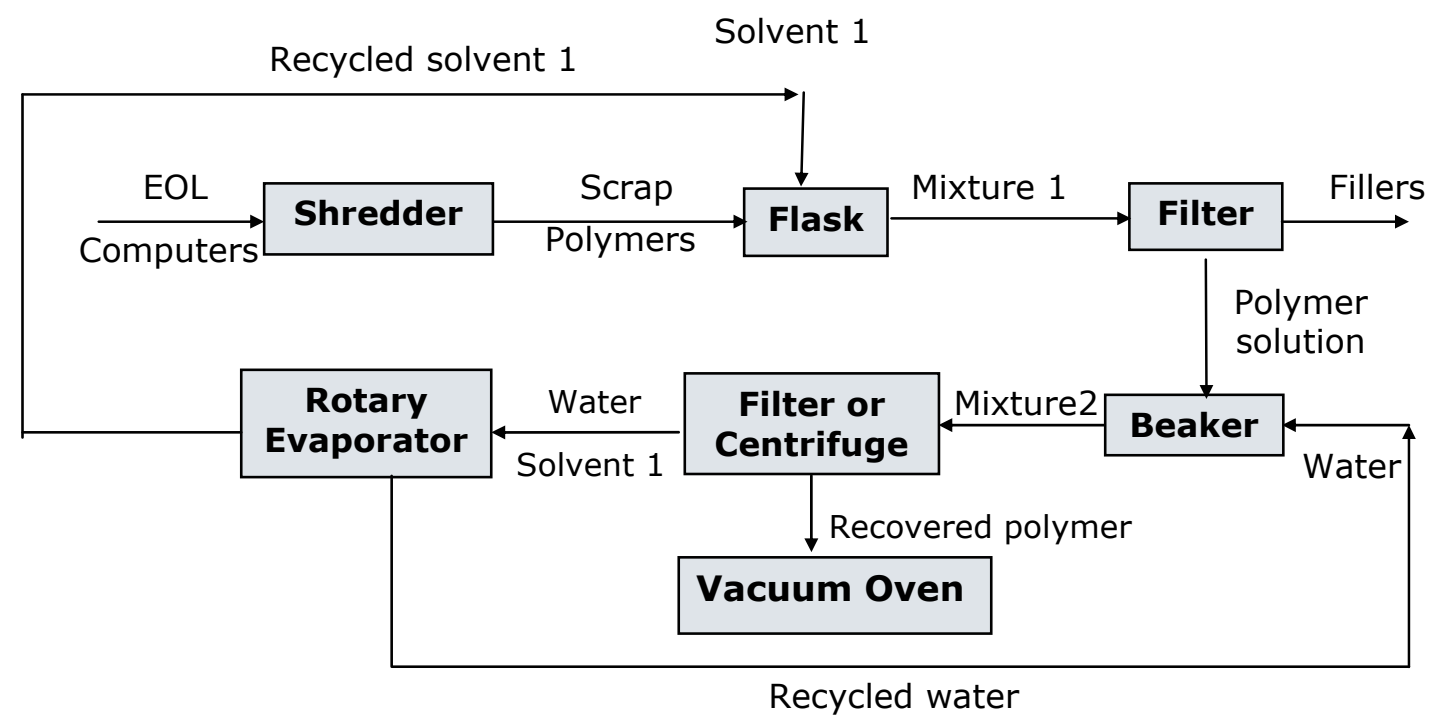

Figure 3.11 Basic experimental steps needed to obtain the calibration curve

As shown in Figure 3.11, EOL computers are chosen as representative samples of EOL electronics. First, the obsolete computers are dismantled by hand, and then shredded into polymer scraps and the scraps are collected. Then samples of known amounts of different polymer are dissolved in an appropriate solvent. The solvent used to dissolve the polymer for the calibration curve is NMP $\left(\mathrm{C}_{5} \mathrm{H}_{9} \mathrm{NO}\right)$. The reason that NMP is selected is that PC, PS and ABS can be easily dissolved in NMP. The mixture thus obtained is then filtered, which allows some inorganic filler to be separated from the solution. Adding water to the solution or evaporating the solvent precipitates the polymer. The solid particles of polymer are separated by filtration or centrifugation, and then dried in a vacuum oven. By following this procedure, homogeneous polymer mixtures may be obtained. Subsequently, the mixture is analyzed in order to obtain the purity of recycled polymer in the mixture. Analysis of polymer is accomplished by elemental analysis. 
- Material balance

In order to ensure that experiments are being performed correctly, it is required that a mass balance should be satisfied for each experiment. Results of just one group of experiments are shown here to demonstrate that the calibration curve experiments are conducted correctly. Some mixtures of PC and PS with different known ratios are taken as samples and dissolved in NMP. By following the procedure described in 3.7.2, homogeneous mixtures of PC and PS and inorganic fillers are obtained, and then weighed. The material balances, listed in Table 3.2, show that each experiment performed to date has a recovery better than $93 \%$ with an average recovery of $96.8 \%$.

Table 3.2 Material Balance of calibration curve experiment

\begin{tabular}{|c|c|c|c|c|}
\hline $\begin{array}{c}\text { PC\% in PC/PS } \\
\text { mixture }\end{array}$ & $\begin{array}{c}\text { Sample } \\
\text { weight }(\mathrm{g})\end{array}$ & $\begin{array}{c}\text { Recovered } \\
\text { sample weight }(\mathrm{g})\end{array}$ & $\begin{array}{c}\text { Inorganic filler } \\
\text { weight }(\mathrm{g})\end{array}$ & $\begin{array}{c}\text { Recovery } \\
(\%)\end{array}$ \\
\hline 0.00 & 5 & 4.9 & 0 & 98 \\
\hline 0.25 & 10 & 8.7 & 0.7 & 94 \\
\hline 0.50 & 10 & 7.9 & 1.4 & 93 \\
\hline 0.75 & 10 & 8.3 & 1.6 & 99 \\
\hline 1.00 & 5 & 3.9 & 1.1 & 100 \\
\hline
\end{tabular}

Note: Sample: 1. HP680 Rough Grey PC 2. Fujitsu Limited PS

Undissolved filler was analyzed to ensure that no organic material is left in the filler, i.e. all of organic material dissolved in solvent. The results shown in Table 4.5 indicate the inorganic materials in the sample PC. PS also has some inorganic filler, but the amount of the filler was too small to collect.

Table 3.3 Inorganic components in PC

\begin{tabular}{|c|c|c|c|c|}
\hline Sample & $\mathrm{Si}(\mathrm{mg} / \mathrm{kg})$ & $\mathrm{Ca}(\mathrm{mg} / \mathrm{kg})$ & $\mathrm{Na}(\mathrm{mg} / \mathrm{kg})$ & $\mathrm{K}(\mathrm{mg} / \mathrm{kg})$ \\
\hline Hp 680 Rough Grey PC & 71,884 & 86,178 & 17,778 & $1,367.2$ \\
\hline
\end{tabular}


- $\quad$ PC and PS calibration curve

Calibration curves are used to predict the purity of recovered polymers. For a binary mixture of polymers, a theoretical curve can be obtained based on the oxygen content of the mixture.

The oxygen percent of PC and PS mixture with different ratios was analyzed by an Elemental Analyzer (EA) to generate the calibration curve of PC and PS. The calibration curve based on the experimental data is shown in Figure 3.12.

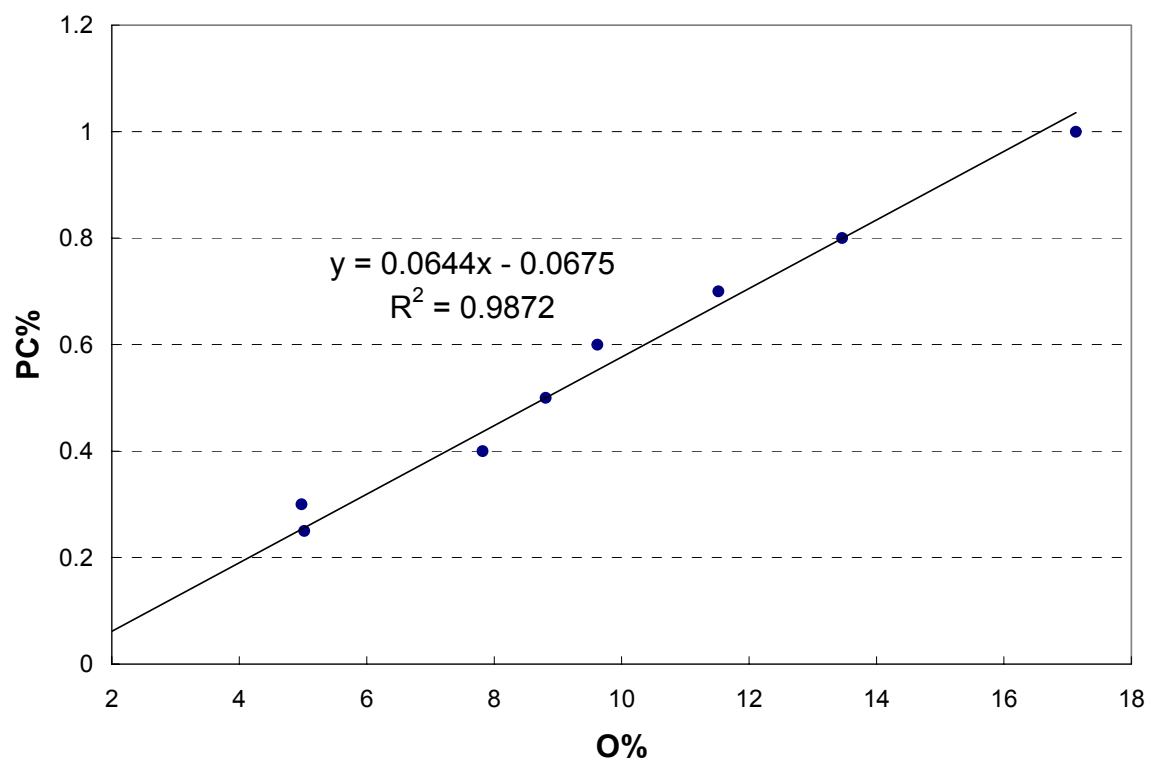

Figure 3.12 Calibration curve of PC/PS

A linear equation is obtained between oxygen percent and PC percent in the mixture. The result confirms that elemental analysis can be used to measure the purity of the recycled polymer. 
- $\quad$ C and ABS Calibration Curve

The same calibration curve experiments were also performed with PC and ABS. The calibration curve is shown in Figure 3.13.

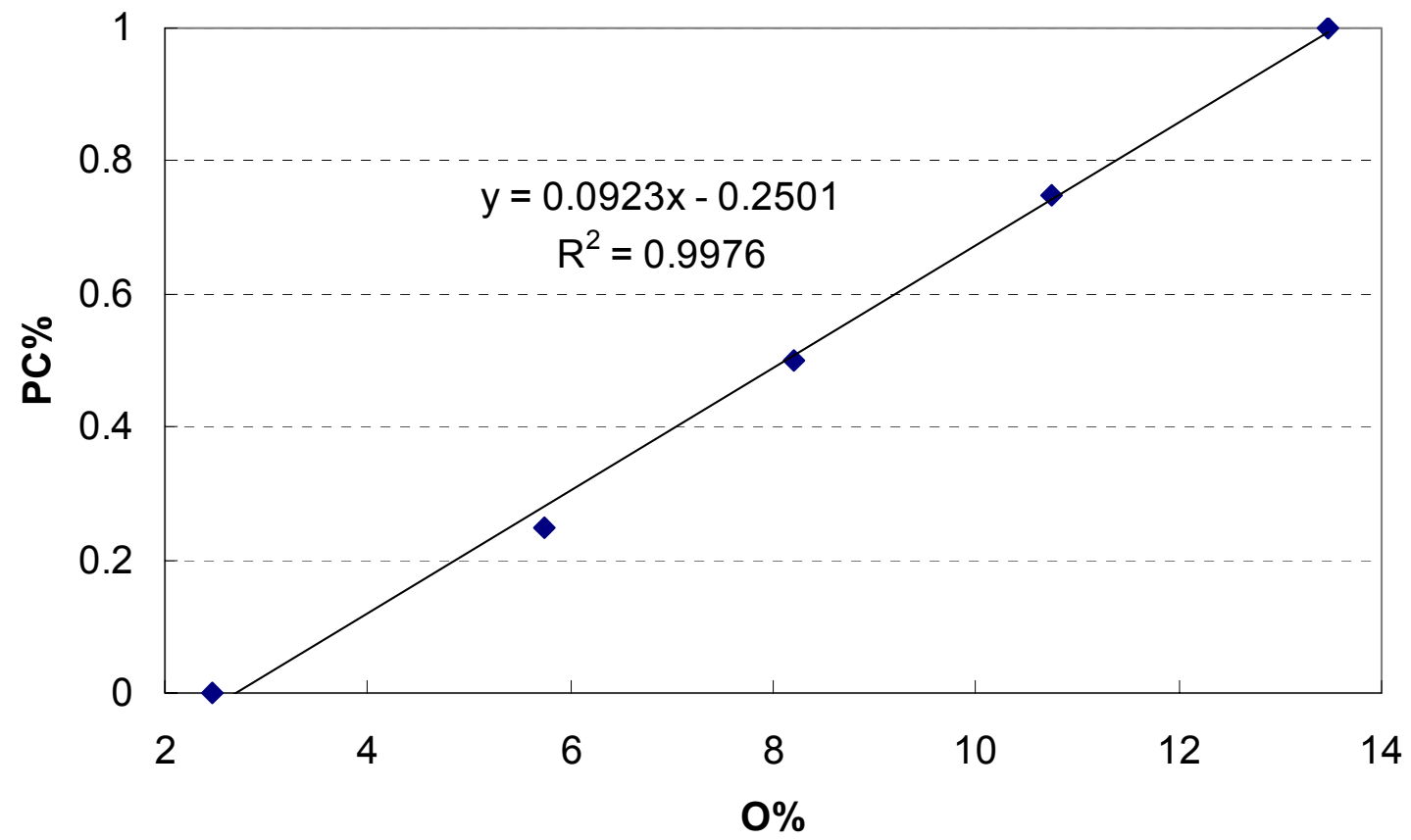

Figure 3.13 Calibration curve of PC/ABS 


\section{Results and Discussions}

\subsection{Choice of organic solvents and antisolvents}

After the Plastic samples were collected and identified, the next step was to decide which solvents were best for the separation of the mixed plastics. There are a number of factors that should be considered when choosing organic solvents. The solubility parameter of the polymer and solvent is the first factor. Polymers are generally soluble in solvents if the difference between the solubility parameters is less than approximately $0.9\left(\mathrm{cal} / \mathrm{cm}^{3}\right)^{1 / 2}$ (Barton [1985]). But similar solubility parameters do not guarantee that the polymer will dissolve in the solvent. Therefore other factors must be taken into account, such as the polarity and the molecular structure of the polymer, safety data, recoverability and environmental behavior of solvent, etc.

In this research, several organic solvents for PS, PC and ABS were identified and investigated. The solubility parameters of three selected polymers and investigated solvents are listed in Table 4.1.

Table 4.1 The solubility parameter of solvents and polymers (Barton [1985]).

\begin{tabular}{|c|c|c|c|}
\hline Solvent & $\begin{array}{c}\text { Solubility Parameter } \\
\left(\mathrm{cal}^{3} \mathrm{~cm}^{3}\right)^{1 / 2}\end{array}$ & polymer & $\begin{array}{c}\text { Solubility Parameter } \\
\left(\mathrm{cal} / \mathrm{cm}^{3}\right)^{1 / 2}\end{array}$ \\
\hline Cyclohexane & 8.2 & PS & 8.6 \\
Carbon Tetrachloride & 8.6 & ABS & 9.1 \\
2-Butanone & 9.3 & PC & $9.3-10.3$ \\
Acetone & 9.77 & & \\
Carbon Disulfide & 9.98 & & \\
NMP & 11.42 & & \\
\hline
\end{tabular}

PS is a non-polar polymer and is soluble in many non-polar organic solvents. So cyclohexane and carbon tetrachloride, which are non-polar solvents, are chosen to dissolve PS. By comparing the solubility parameters shown in Table 4.1, carbon 
tetrachloride $\left(\mathrm{CCl}_{4}\right)$ and cyclohexane $\left(\mathrm{C}_{6} \mathrm{H}_{12}\right)$ appear to be suitable for the selective dissolution of PS( Billmeyer [1985], Alfery and Gurnee [1973]). It is shown that acetone can be used to extract ABS at ambient temperature and pressure (Jody et al. [1994]).

For a ternary mixture of PC, PS and ABS, if two of the polymers can be dissolved separately, then it is not necessary to dissolve the third component. So the solubility of PC in listed solvents was checked in this project. To make sure these selected solvents can work, some very simple experiments were carried out to check the solubility of polymers in these solvents.

1 gram of each polymer was taken and added to $100 \mathrm{ml}$ of each solvent at room temperature and normal pressure. Results of these experiments are shown in Table 4.2.

Table 4.2 Solubility of polymers at room temperature

\begin{tabular}{|c|c|c|c|c|c|c|}
\hline & NMP & $\begin{array}{c}\text { Carbon } \\
\text { Disulfide }\end{array}$ & $\begin{array}{c}\text { Carbon } \\
\text { Tetrachloride }\end{array}$ & Acetone & Cyclohexane & $\begin{array}{c}2- \\
\text { Butanone }\end{array}$ \\
\hline PS & + & + & + & - & $+\left(80^{\circ} \mathrm{C}\right)$ & + \\
\hline PC & + & - & - & - & - & - \\
\hline ABS & + & - & - & + & - & + \\
\hline
\end{tabular}

Note: +: Soluble; -: Insoluble

From Table 4.2, it is found that PS can be dissolved in all of the solvents except acetone, and only ABS can be dissolved in acetone. So acetone is the best choice for separation of ABS from PC and PS. In NMP, all of three polymers can be dissolved so that a mixture of these three polymers cannot be separated with NMP. Carbon disulfide, carbon tetrachloride and cyclohexane are good for PS separation because only PS can be dissolved in these solvents. However, carbon disulfide and carbon tetrachloride were not considered further because of their high toxicity. Because 2-butanone can dissolve both PS and ABS, it will not work in a separation experiment for PS from ABS. Finally, 
cyclohexane at its boiling point is selected as the solvent to dissolve PS, and acetone at room temperature is used to dissolve ABS.

The dissolved polymer can be precipitated out of solution by adding antisolvents or evaporating the solvent. Only the process of adding antisolvents will be used since it is easier to operate in the laboratory. Since almost all polymers do not dissolve in water, the first choice of antisolvent would be the cheapest, namely water. Simple experiment showed that water can be the antisolvent for ABS in acetone. But water does not work for PS in cyclohexane because water and cyclohexane are immiscible. Therefore, ethanol is chosen to be the antisolvent for PS in cyclohexane.

In summary, cyclohexane and acetone are chosen as solvents, ethanol and water act as the respective antisolvents in the work. Acetone, cyclohexane and ethanol were brought from Fisher Scientific Corporation.

\subsection{Optimized experimental conditions}

In order to determine the best combinations of dissolution time, temperature, and volume of solvents and antisolvents, a set of scoping experiments was performed and is discussed below. Drying conditions for the separated polymers were also investigated.

\subsubsection{Dissolution scoping studies}

In Table 4.3, 1 gram of PS was taken and dissolved in $100 \mathrm{ml}$ cyclohexane at different temperatures, and for different times, experimental phenomena were observed and compared to determine appropriate conditions to be used in future work. The amount of PS that can be dissolved in cyclohexane was also investigated. 


\section{Table 4.3 Experimental conditions for dissolution of PS in cyclohexane}

\begin{tabular}{|c|c|c|c|c|}
\hline Weight $(\mathrm{g})$ & 1 & 2 & 3 & N/A \\
\hline Temperature $\left({ }^{\circ} \mathrm{C}\right)$ & 25 & 50 & 80 & N/A \\
\hline Time $(\min )$ & 15 & 30 & 45 & 60 \\
\hline
\end{tabular}

Results in Table 4.4 show that cyclohexane has to be heated to its boiling point to dissolve PS effectively.

Table 4.4 Solubility of PS at different temperatures

\begin{tabular}{|c|c|c|c|}
\hline Temperature $\left({ }^{\circ} \mathrm{C}\right)$ & 25 & 50 & 80 \\
\hline phenomena & Not dissolved & Not dissolved & Dissolved \\
\hline
\end{tabular}

1 gram of PS was taken and dissolved in $100 \mathrm{ml}$ cyclohexane at $80^{\circ} \mathrm{C}$; results were observed and recorded at 15-minute intervals for 1 hour. It was found that after 15, 30, and 45 minutes, only part of the PS dissolved. After1 hour, all the PS disappeared.

In order to determine how much PS can be dissolved in cyclohexane, $1 \mathrm{~g}, 2 \mathrm{~g}$ and $3 \mathrm{~g}$ of PS were separately added to $100 \mathrm{ml}$ cyclohexane, heated to $80{ }^{\circ} \mathrm{C}$, and allowed to equilibrate for 1 hour. It was found that for $2 \mathrm{~g}$ and $3 \mathrm{~g}$ samples of PS, only part of PS dissolved.

For ABS in acetone, since it has already been shown that ABS can be dissolved in acetone at room temperature, it is not necessary to check the relationship between solubility and temperature. Experiments were conducted with $100 \mathrm{ml}$ acetone at room temperature. How much ABS can be dissolved in 100ml acetone and the time needed to dissolve ABS completely was estimated. Table 4.5 shows the conditions of these experiments.

Table 4.5 Experimental conditions for dissolution of ABS in Acetone

\begin{tabular}{|c|c|c|c|}
\hline Weight of ABS $(\mathrm{g})$ & 1 & 2 & 3 \\
\hline Time $(\mathrm{min})$ & 15 & 30 & 45 \\
\hline
\end{tabular}


1 gram of $\mathrm{ABS}$ was taken and added to $100 \mathrm{ml}$ of acetone at room temperature, the mixture was stirred for 15 minutes, and a portion of the ABS dissolved. Stirring was continued for another 15 minutes at which time all the ABS disappeared. Therefore, 1 gram of ABS can be completely dissolved in $100 \mathrm{ml}$ acetone in 30 minutes.

2 grams, 3 grams of ABS were each added into $100 \mathrm{ml}$ acetone, and stirred for half hour. It was found that after 30 minutes, 2grams of ABS dissolved completely, but the 3 grams of ABS was not dissolved completely. It was also noticed that the solution of 2 gram of ABS in acetone was very thick. This is not good for filtration, so it was decided to add only 1 gram of ABS to $100 \mathrm{ml}$ of acetone.

Based on the results of these experiments, 10 grams of each plastic mixture were taken to perform the separation experiments, optimized conditions for the separation experiments are summarized in Table 4.6.

Table 4.6 Dissolution conditions for separation experiments

\begin{tabular}{|c|c|c|c|c|c|c|c|}
\hline $\begin{array}{c}\text { Plastic } \\
\text { mixtures }\end{array}$ & Ratio & Solvent & $\begin{array}{c}\text { Volume of } \\
\text { solvent }(\mathrm{ml})\end{array}$ & $\begin{array}{c}\text { Anti- } \\
\text { solvent }\end{array}$ & $\begin{array}{c}\text { Volume of } \\
\text { antisolvent }(\mathrm{ml})\end{array}$ & $\begin{array}{c}\text { Temperature } \\
\left({ }^{\circ} \mathrm{C}\right)\end{array}$ & $\begin{array}{c}\text { Time } \\
(\mathrm{h})\end{array}$ \\
\hline $\mathrm{PC} / \mathrm{PS}$ & $9 / 1$ & Cyclohexane & 100 & Ethanol & 50 & 80 & 1 \\
\hline $\mathrm{PC} / \mathrm{ABS}$ & $9 / 1$ & Acetone & 100 & Water & 100 & 25 & 0.5 \\
\hline $\mathrm{PC} / \mathrm{PS}$ & $9 / 0.5$ & Acetone & 50 & Water & 50 & 25 & 0.5 \\
\cline { 2 - 8 }$/ \mathrm{ABS}$ & $/ 0.5$ & Cyclohexane & 50 & Ethanol & 25 & 80 & 1 \\
\hline
\end{tabular}

From Table 4.6, it was decided that 1 gram of PS would be dissolved in $100 \mathrm{ml}$ of cyclohexane at its boiling point. 1 gram of ABS will be dissolved in $100 \mathrm{ml}$ of acetone at room temperature. The volume of solvents used depends only on how much PS and ABS are in the mixture no matter what is the composition of the polymer. Based on the volume of solvents used, volumes of antisolvents needed were also investigated by 
adding antisolvents gradually into the polymer solution and check how much polymer precipitated out. The results were also listed in table 4.6.

\subsubsection{Drying Conditions Studies}

Separated polymer is dried in a vacuum oven. Solvents to be evaporated in the vacuum oven are water, cyclohexane, acetone, and ethanol. In order to find the most effective way to dry polymers, the relationship between vapor pressure of the three solvents and temperature was investigated before drying.

From Yaws [1999], results for vapor pressure as a function of temperature are presented. The Antoine-type equation with extended terms was used to predict the vapor pressure as a function of temperature:

$$
\log P=A+B / T+C \log T+D T+E T^{2}
$$

Where $\quad \mathrm{P}=$ vapor pressure, $\mathrm{mmHg}$

$\mathrm{A}, \mathrm{B}, \mathrm{C}, \mathrm{D}$, and $\mathrm{E}=$ regression coefficients for chemical compound $\mathrm{T}=$ temperature, $\mathrm{K}$

The results for vapor pressure are given in Table 4.3 and calculated values for vapor pressure are shown in Figure 4.1.

Table 4.7 Experimental data for vapor pressure of organic solvents

\begin{tabular}{|c|c|c|c|c|c|c|}
\hline Formula & Name & A & B & C & D & E \\
\hline $\mathrm{C}_{2} \mathrm{H}_{6} \mathrm{O}$ & ethanol & 23.8442 & $-2.8642 \mathrm{E}+03$ & -5.0474 & $3.7448 \mathrm{E}-11$ & $2.7361 \mathrm{E}-07$ \\
\hline $\mathrm{C}_{3} \mathrm{H}_{6} \mathrm{O}$ & acetone & 28.5884 & $-2.4690 \mathrm{E}+03$ & -7.3510 & $2.8025 \mathrm{E}-10$ & $2.7361 \mathrm{E}-06$ \\
\hline $\mathrm{C}_{6} \mathrm{H}_{12}$ & cyclohexane & 48.5529 & $-3.0874 \mathrm{E}+03$ & $-1.5221 \mathrm{E}+01$ & $7.3830 \mathrm{E}-03$ & $6.3563 \mathrm{E}-12$ \\
\hline
\end{tabular}




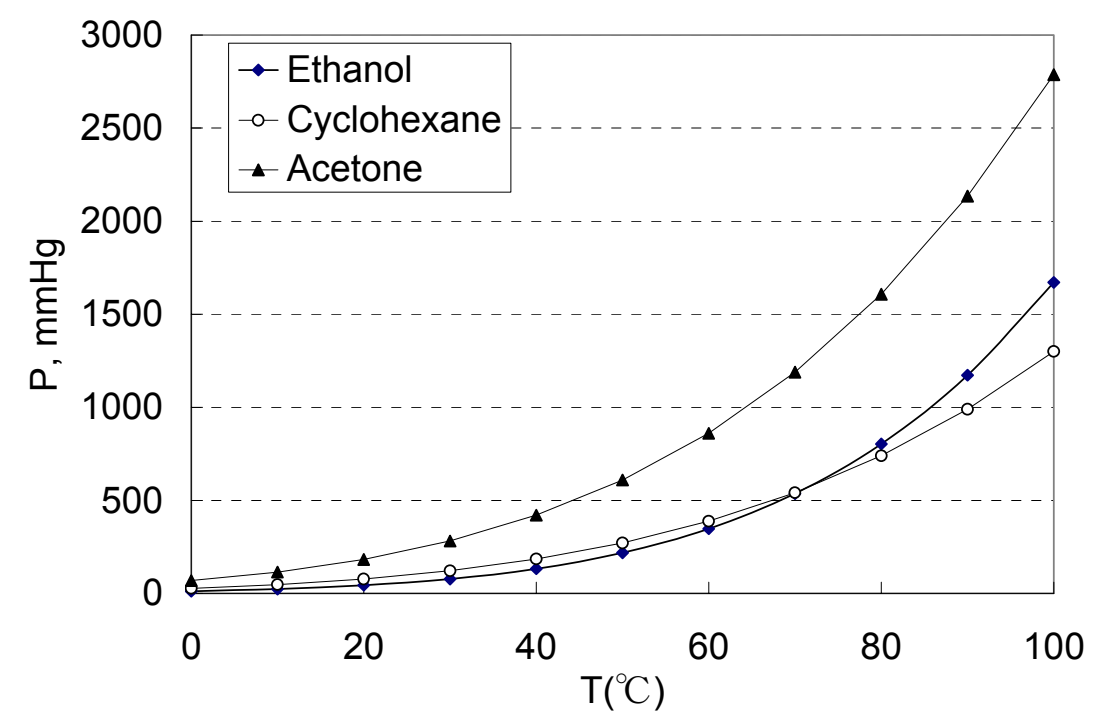

Figure 4.1 Vapor pressure relationship as a function of temperature for three

\section{different solvents}

As shown in Figure 4.1, it is clear that all three solvents are very volatile. If the pressure of the vacuum oven is set to $200 \mathrm{mmHg}$, a temperature of $50^{\circ} \mathrm{C}$ is sufficient to evaporate all of these solvents.

Also, in order to save time and energy, the relationship between weight of dried polymers and drying time was investigated. The results for the drying experiments are given in Figures 4.2-4.5. In Figures 4.2 and 4.3, PC and PS were separated from a mixture of PC/PS. In Figures 4.4 and 4.5, PC and ABS were separated from a mixture of PC/ABS. 


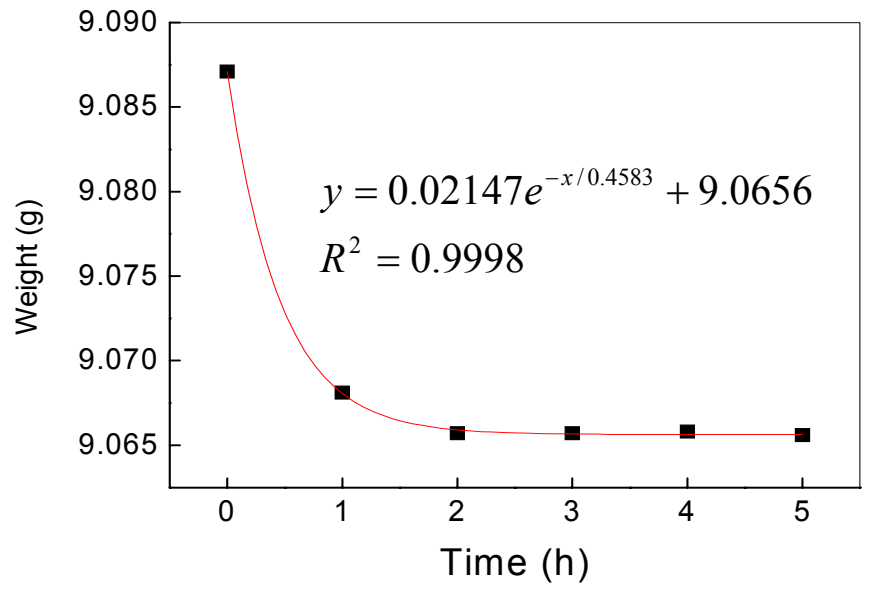

Figure 4.2 The Relationship of PC Weight with Drying Time

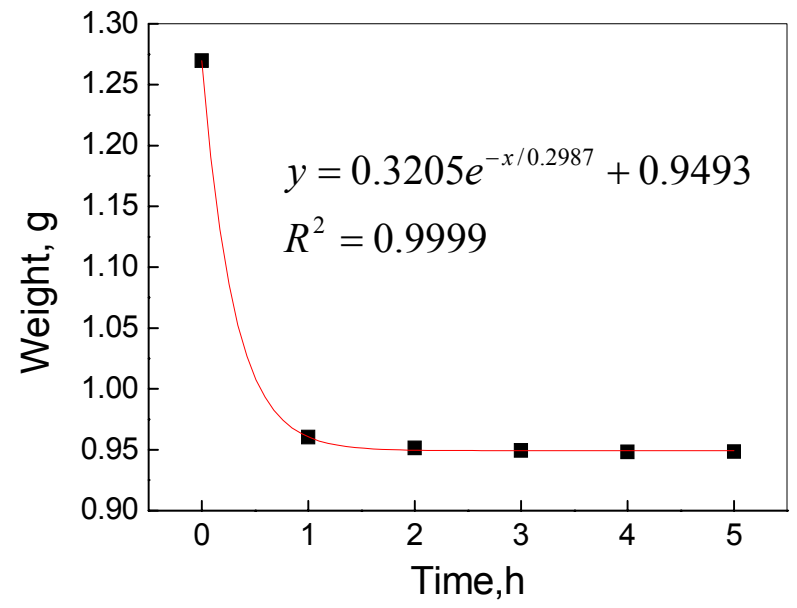

Figure 4.3 The Relationship of PS Weight with Drying Time

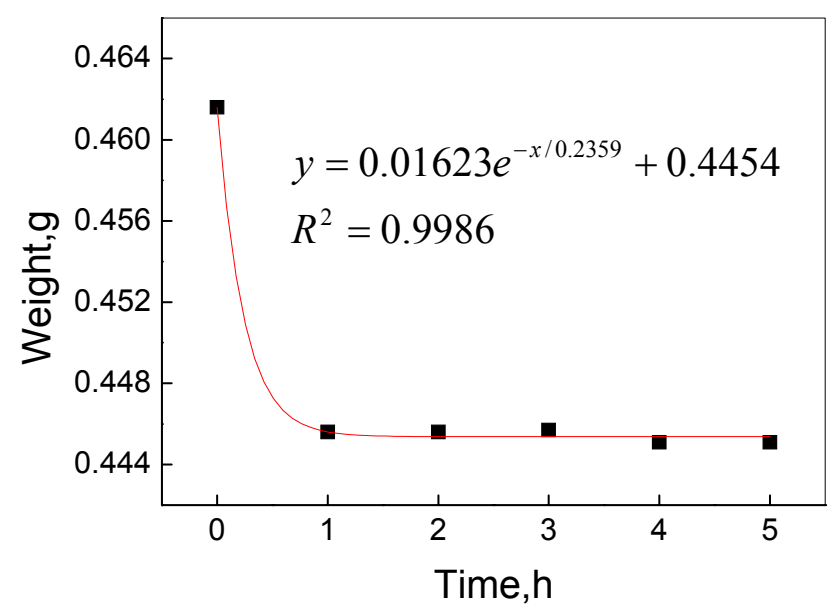

Figure 4.4 The Relationship of PC Weight with Drying Time 


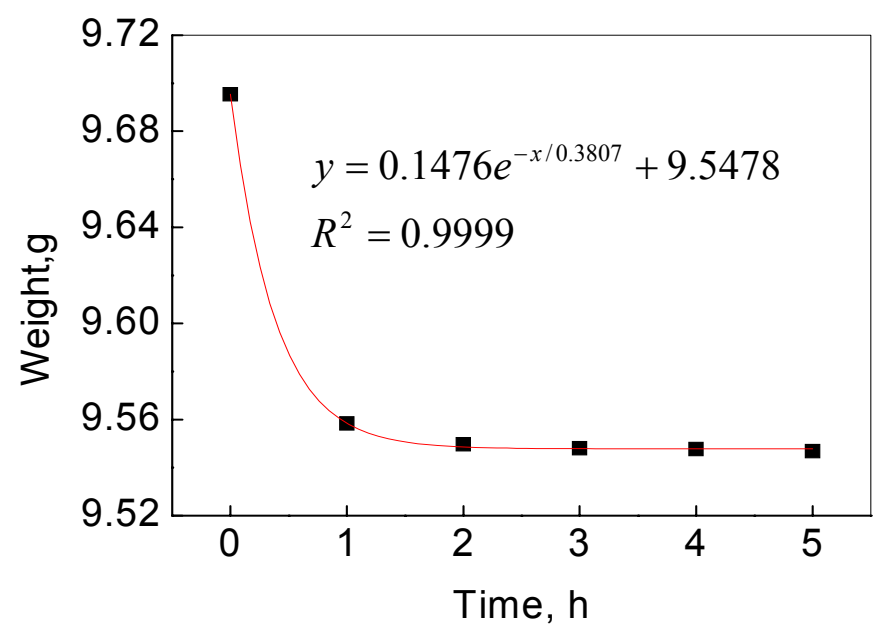

Figure 4.5 The Relationship of ABS Weight with Drying Time

From the Figures 4.2-4.5, it was found that after 2 hours of drying, the weight of polymers remains constant, indicating that all the solvent that can be removed by evaporation has been removed. After 1 hour of drying, there is not much weight loss. Therefore, in order to save energy, the separated polymers will be dried for 1 hour.

Therefore in this work, the separated polymers are dried for one hour in a vacuum oven at a pressure of $200 \mathrm{mmHg}$ and temperature $50^{\circ} \mathrm{C}$. Under these conditions, about $0.13 \mathrm{wt} \%$ of solvents is lost during the drying process.

\subsection{Separation experiment results}

\subsubsection{Material Balance}

Three groups of separation experiments were carried out with mixtures of $\mathrm{PC} / \mathrm{PS}=9 / 1, \mathrm{PC} / \mathrm{ABS}=9 / 1$ and $\mathrm{PC} / \mathrm{PS} / \mathrm{ABS}=9 / 0.5 / 0.5$. Three replicate experiments are done for each mixture. Material and oxygen balances were always performed for each experiment. 
10 grams of a plastic mixture, 9 grams of $\mathrm{PC}$ and 1 gram of $\mathrm{PS}$, are taken to perform the separation experiment. Material balances for three replicate experiments are shown in Table 4.8.

Table 4.8 Material balances of separation experiments with $\mathrm{PC} / \mathrm{PS}=9 / 1$

\begin{tabular}{|c|c|c|c|c|}
\hline No. & $\begin{array}{l}\text { Recycled } \\
\text { PC }(\mathrm{g})\end{array}$ & $\begin{array}{l}\text { Recycled } \\
\text { PS }(\mathrm{g})\end{array}$ & $\begin{array}{l}\text { Total Recycled } \\
\text { Polymer Weight }(\mathrm{g})\end{array}$ & $\begin{array}{c}\text { Recovery } \\
(\%)\end{array}$ \\
\hline 1 & 8.90 & 1.00 & 9.90 & 99.00 \\
\hline 2 & 9.00 & 0.95 & 9.95 & 99.50 \\
\hline 3 & 9.02 & 0.72 & 9.74 & 97.40 \\
\hline
\end{tabular}

As shown in Table 4.8, each separation experiment has a recovery better than $97 \%$ with an average recovery of $98.63 \%$. In addition, oxygen balances based on the material balance in Table 4.8 were also checked and shown in Table 4.9. The oxygen weight in Table 4.9 is the amount of oxygen in each sample, and the total oxygen weight is the sum of oxygen weight of each sample in the mixture. Recovery is the ratio of total oxygen weight of separated sample to that of original sample. The results listed in Table 4.9 show that the material balance for oxygen closes to within less than $4 \%$. An average oxygen recovery of $97.27 \%$ proved that it is possible to use an oxygen analysis to determine the purity of recovered polymers.

Table 4.9 Oxygen balances of separation experiments with $\mathrm{PC} / \mathrm{PS}=9 / 1$

\begin{tabular}{|c|c|c|c|c|c|c|c|}
\hline \multicolumn{2}{|c|}{$\begin{array}{c}\text { Separation } \\
\text { Experiment } \\
\text { No. }\end{array}$} & $\begin{array}{c}\text { Name of } \\
\text { sample }\end{array}$ & $\begin{array}{l}\text { Weight of } \\
\text { sample }(\mathrm{g})\end{array}$ & $\begin{array}{l}\mathrm{O} \% \text { of } \\
\text { sample }\end{array}$ & $\begin{array}{c}\text { Oxygen } \\
\text { weight }(\mathrm{g})\end{array}$ & $\begin{array}{c}\text { Total } \\
\text { oxygen } \\
\text { weight }\end{array}$ & $\begin{array}{c}\text { Recovery } \\
(\%)\end{array}$ \\
\hline \multirow{2}{*}{\multicolumn{2}{|c|}{ Sample }} & $\mathrm{PC}$ & 9.00 & 13.48 & 1.2132 & \multirow{2}{*}{1.2232} & \multirow{2}{*}{ N/A } \\
\hline & & PS & 1.00 & 1.00 & 0.0069 & & \\
\hline \multirow{6}{*}{$\begin{array}{l}\text { Separated } \\
\text { sample }\end{array}$} & \multirow{2}{*}{1} & $\mathrm{PC}$ & 8.90 & 13.18 & 1.1730 & \multirow{2}{*}{1.1806} & \multirow{2}{*}{96.52} \\
\hline & & PS & 1.00 & 0.76 & 0.0076 & & \\
\hline & \multirow{2}{*}{2} & $\mathrm{PC}$ & 9.00 & 13.20 & 1.1880 & \multirow{2}{*}{1.1964} & \multirow{2}{*}{97.81} \\
\hline & & PS & 0.95 & 0.88 & 0.0084 & & \\
\hline & \multirow{2}{*}{3} & $\mathrm{PC}$ & 9.02 & 13.16 & 1.1870 & \multirow{2}{*}{1.1924} & \multirow{2}{*}{97.48} \\
\hline & & PS & 0.72 & 0.75 & 0.0054 & & \\
\hline
\end{tabular}


For the separation experiments with $\mathrm{PC} / \mathrm{ABS}=9 / 1$, an average material recovery of $99.30 \%$ and an average oxygen recovery of $99.15 \%$ was found. The experimental data of material and oxygen balance were listed in Table 4.10 and Table 4.11.

Table 4.10 Material balances of separation experiment with $\mathrm{PC} / \mathrm{ABS}=9 / 1$

\begin{tabular}{|c|c|c|c|c|c|c|c|}
\hline No. & $\begin{array}{c}\text { PC } \\
\text { Weight } \\
(\mathrm{g})\end{array}$ & $\begin{array}{c}\text { ABS } \\
\text { Weight } \\
(\mathrm{g})\end{array}$ & $\begin{array}{c}\text { Total } \\
\text { Weight } \\
(\mathrm{g})\end{array}$ & $\begin{array}{c}\text { Recycled } \\
\text { PC } \\
(\mathrm{g})\end{array}$ & $\begin{array}{c}\text { Recycled } \\
\text { ABS } \\
(\mathrm{g})\end{array}$ & $\begin{array}{c}\text { Total Recycled } \\
\text { Polymer Weight } \\
(\mathrm{g})\end{array}$ & $\begin{array}{c}\text { Recovery } \\
(\%)\end{array}$ \\
\hline 1 & 9.00 & 1.00 & 10.00 & 9.10 & 0.70 & 9.80 & 98.00 \\
\hline 2 & 9.00 & 1.00 & 10.00 & 9.00 & 1.00 & 10.00 & 100.00 \\
\hline 3 & 9.00 & 1.00 & 10.00 & 9.15 & 0.84 & 10.00 & 99.90 \\
\hline
\end{tabular}

Table 4.11 Oxygen balances of separation experiment with $\mathrm{PC} / \mathrm{ABS}=9 / 1$

\begin{tabular}{|c|c|c|c|c|c|c|c|}
\hline \multicolumn{2}{|c|}{$\begin{array}{c}\text { Experiment } \\
\text { No. }\end{array}$} & $\begin{array}{c}\text { Name of } \\
\text { sample }\end{array}$ & $\begin{array}{r}\text { Weight of } \\
\text { sample }(\mathrm{g})\end{array}$ & $\begin{array}{l}\mathrm{O} \% \text { of } \\
\text { sample }\end{array}$ & $\begin{array}{c}\text { Oxygen } \\
\text { weight }(\mathrm{g})\end{array}$ & $\begin{array}{c}\text { Total oxygen } \\
\text { weight }\end{array}$ & $\begin{array}{c}\text { Recovery } \\
(\%)\end{array}$ \\
\hline \multirow{2}{*}{\multicolumn{2}{|c|}{ Sample }} & $\mathrm{PC}$ & 9.00 & 13.48 & 1.2132 & \multirow{2}{*}{1.2378} & \multirow{2}{*}{ N/A } \\
\hline & & ABS & 1.00 & 2.46 & 0.0246 & & \\
\hline \multirow{6}{*}{$\begin{array}{l}\text { Separated } \\
\text { sample }\end{array}$} & \multirow{2}{*}{1} & $\mathrm{PC}$ & 9.10 & 13.20 & 1.2012 & \multirow{2}{*}{1.2261} & \multirow{2}{*}{99.05} \\
\hline & & $\mathrm{ABS}$ & 0.70 & 3.55 & 0.0249 & & \\
\hline & \multirow{2}{*}{2} & $\mathrm{PC}$ & 9.00 & 13.18 & 1.1862 & \multirow{2}{*}{1.2197} & \multirow{2}{*}{98.54} \\
\hline & & $\mathrm{ABS}$ & 1.00 & 3.35 & 0.0335 & & \\
\hline & 3 & $\mathrm{PC}$ & 9.15 & 13.19 & 1.2069 & \multirow{2}{*}{1.2360} & \multirow{2}{*}{99.85} \\
\hline & 3 & $\mathrm{ABS}$ & 0.84 & 3.46 & 0.0291 & & \\
\hline
\end{tabular}

For the separation experiments with $\mathrm{PC} / \mathrm{PS} / \mathrm{ABS}=9 / 0.5 / 0.5,96.23 \%$ material recovery and $95.82 \%$ oxygen recovery were found. Experimental data for PC/PS/ABS separation experiments are shown in Table 4.12 and Table 4.13 .

Table 4.12 Material Balances of separation experiment with $\mathrm{PC} / \mathrm{PS} / \mathrm{ABS}=9 / 0.5 / 0.5$

\begin{tabular}{|c|c|c|c|c|c|c|c|c|c|}
\hline No. & $\begin{array}{c}\text { PC } \\
\text { Weight } \\
(\mathrm{g})\end{array}$ & $\begin{array}{c}\text { PS } \\
\text { Weight } \\
(\mathrm{g})\end{array}$ & $\begin{array}{c}\text { ABS } \\
\text { Weight } \\
(\mathrm{g})\end{array}$ & $\begin{array}{c}\text { Total } \\
\text { Weight } \\
(\mathrm{g})\end{array}$ & $\begin{array}{c}\text { Recycled } \\
\text { PC } \\
(\mathrm{g})\end{array}$ & $\begin{array}{c}\text { Recycled } \\
\text { PS } \\
(\mathrm{g})\end{array}$ & $\begin{array}{c}\text { Recycled } \\
\text { ABS } \\
(\mathrm{g})\end{array}$ & $\begin{array}{c}\text { Total Recycled } \\
\text { Polymer Weight } \\
(\mathrm{g})\end{array}$ & $\begin{array}{c}\text { Recovery } \\
(\%)\end{array}$ \\
\hline 1 & 9.00 & 0.50 & 0.50 & 10.00 & 8.75 & 0.30 & 0.45 & 9.50 & 95.00 \\
\hline 2 & 9.00 & 0.50 & 0.50 & 10.00 & 9.00 & 0.40 & 0.40 & 9.80 & 98.00 \\
\hline 3 & 9.00 & 0.50 & 0.50 & 10.00 & 8.70 & 0.40 & 0.47 & 9.57 & 95.70 \\
\hline
\end{tabular}


Table 4.13 Oxygen Balances of separation experiment with $\mathrm{PC} / \mathrm{PS} / \mathrm{ABS}=9 / 0.5 / 0.5$

\begin{tabular}{|c|c|c|c|c|c|c|c|}
\hline \multicolumn{2}{|c|}{$\begin{array}{c}\text { Experiment } \\
\text { No. }\end{array}$} & $\begin{array}{c}\text { Name of } \\
\text { sample }\end{array}$ & $\begin{array}{l}\text { Weight of } \\
\text { sample }(g)\end{array}$ & $\begin{array}{l}\mathrm{O} \% \text { of } \\
\text { sample }\end{array}$ & $\begin{array}{c}\text { Oxygen } \\
\text { weight }(\mathrm{g})\end{array}$ & $\begin{array}{c}\text { Total oxygen } \\
\text { weight }\end{array}$ & $\begin{array}{c}\text { Recovery } \\
(\%)\end{array}$ \\
\hline \multirow{3}{*}{\multicolumn{2}{|c|}{ Sample }} & $\mathrm{PC}$ & 9.00 & 13.48 & 1.2132 & \multirow{3}{*}{1.2305} & \multirow{3}{*}{$\mathrm{N} / \mathrm{A}$} \\
\hline & & PS & 0.50 & 1.00 & 0.0050 & & \\
\hline & & ABS & 0.50 & 2.46 & 0.0123 & & \\
\hline \multirow{9}{*}{$\begin{array}{l}\text { Separated } \\
\text { sample }\end{array}$} & \multirow{3}{*}{1} & $\mathrm{PC}$ & 8.75 & 12.80 & 1.1200 & \multirow{3}{*}{1.1340} & \multirow{3}{*}{92.16} \\
\hline & & PS & 0.30 & 0.91 & 0.0027 & & \\
\hline & & ABS & 0.45 & 2.52 & 0.0113 & & \\
\hline & \multirow{3}{*}{2} & $\mathrm{PC}$ & 9.00 & 13.40 & 1.2060 & \multirow{3}{*}{1.2194} & \multirow{3}{*}{99.10} \\
\hline & & PS & 0.40 & 0.85 & 0.0034 & & \\
\hline & & ABS & 0.40 & 2.49 & 0.0100 & & \\
\hline & \multirow{3}{*}{3} & PC & 8.70 & 13.42 & 1.1675 & \multirow{3}{*}{1.1839} & \multirow{3}{*}{96.21} \\
\hline & & PS & 0.40 & 0.82 & 0.0033 & & \\
\hline & & ABS & 0.47 & 2.79 & 0.0131 & & \\
\hline
\end{tabular}

From these data, it is clear that the material balances for the separation experiments close within acceptable limits. It is also noticed that a higher oxygen recovery can be obtained if the material recovery is higher. This reasonable relationship between oxygen recovery and material recovery further proves the correctness of the separation experiments. Recoveries of less than $100 \%$ occur because there is always some loss of material. Very small amount of plastic can be lost in the filtration process because of sticking to the filter paper and this amount of plastic is too small to collect.

\subsubsection{Separation Results}

Since pure polymers do not exist in recycled material, samples used in all separation experiments are analyzed by EA to get the oxygen percent of these samples. Based on these data, purity of recovered polymers was calculated. Table 4.14 shows the EA results of the original samples. All oxygen percentages listed in Tables of section 4.4.2 are average data. 


\section{Table 4.14 Oxygen percentages of original samples}

\begin{tabular}{|c|c|c|c|}
\hline sample & PC & PS & ABS \\
\hline Oxygen $\%$ & 13.48 & 1.00 & 2.46 \\
\hline
\end{tabular}

\section{- $\quad$ PC/PS Separation}

As mentioned in the previous section, 10 grams of plastic mixture with $90 \% \mathrm{PC}$ and $10 \%$ PS were taken to perform the separation experiments. Recycled PC and PS were taken for oxygen analysis by EA. Results of oxygen analysis are shown in Table 4.15 .

Table 4.15 Oxygen analysis results of recycled PC and PS

\begin{tabular}{|c|c|c|}
\hline $\begin{array}{c}\text { No. of } \\
\text { Experiments }\end{array}$ & $\begin{array}{c}\text { O\% in } \\
\text { Recycled PC }\end{array}$ & $\begin{array}{c}\text { O\% in } \\
\text { Recycled PS }\end{array}$ \\
\hline 1 & 13.18 & 0.76 \\
\hline 2 & 13.20 & 0.88 \\
\hline 3 & 13.16 & 0.75 \\
\hline
\end{tabular}

It was noticed that after the separation experiments the percentages of oxygen in recycled PC are all lower than $13.48 \%$, which is the oxygen percent in the original sample. This phenomenon may be explained by the fact that a small amount of PS is left in PC if PS does not dissolve completely, which would result in the decreased oxygen percentage in recycled PC. Another possibility is that there are some impurities in the PS. These impurities contain oxygen but do not dissolve in cyclohexane. They are left in PC during the filtration process, which would also result in lower oxygen content in recycled PC. Moreover, the existence of impurity in PS could also explain why there is oxygen in the original PS sample, and when these impurities are removed, the oxygen percentage in PS is also decreased as shown in Table 4.15.

It was also noticed that after the separation process the oxygen content in PS is also reduced, since impurities that contains oxygen in PS are removed. For this reason, it 
can be said that PS is purified during the separation process. Theoretically, if this lower oxygen percentage is used to calculate the purity of recycled PS, negative results will be obtained. Therefore, the purity of recovered PS cannot be calculated in this work. It is just assumed that the purity of PS is increased to $100 \%$ from $10 \%$ by comparing with the original sample.

The purity of PC must be calculated. Referring to data listed in Tables 4.14 and 4.15 and assuming that there is X percent "pure" PC in recycled PC, from oxygen mass balance, the following equation is obtained:

$$
X \times 13.48+(1-X) \times 1.00=13.18
$$

Hence

$$
X=97.60 \%
$$

In this way, the purity of both recovered polymers is calculated. The results for each experiment are shown in Table 4.16.

Table 4.16 Calculated purity of recycled polymer

\begin{tabular}{|c|c|c|c|c|}
\hline No. of experiment & 1 & 2 & 3 & Average \\
\hline Purity of recycled PC (\%) & 97.60 & 97.76 & 97.44 & 97.60 \\
\hline
\end{tabular}

From Table 4.16, after the separation, the purity of PC is increased from $90 \%$ to an average purity of $97.60 \%$. Estimated purity by calibration curve of PC and PS is not presented here because samples of PC used in the separation are different from the PC used in the calibration curve experiments. Because the oxygen content is different in different samples of PC, this difference cannot be accounted for completely from the experiment by removing inorganic fillers from the original sample. Therefore, different calibration curves should be generated for each different sample. 


\section{$\underline{P C / A B S \text { Separation }}$}

10 grams of plastic mixture with $90 \% \mathrm{PC}$ and $10 \%$ ABS are dissolved in acetone to perform separation experiments. The same purity analysis procedure as described in the PC/PS separation process is followed. Oxygen analysis and purity results are shown in Table 4.17.

Table 4.17 Oxygen analysis results and calculated purities of $\mathrm{PC}$ and ABS

\begin{tabular}{|c|c|c|c|c|}
\hline $\begin{array}{c}\text { No. of } \\
\text { Experiments }\end{array}$ & $\begin{array}{c}\text { O\% in } \\
\text { Recycled PC }\end{array}$ & $\begin{array}{c}\text { O\% in } \\
\text { Recycled ABS }\end{array}$ & $\begin{array}{c}\text { Purity of } \\
\text { Recycled PC } \\
(\%)\end{array}$ & $\begin{array}{c}\text { Purity of } \\
\text { Recycled ABS } \\
(\%)\end{array}$ \\
\hline 1 & 13.20 & 3.55 & 97.46 & 90.11 \\
\hline 2 & 13.18 & 3.35 & 97.28 & 91.94 \\
\hline 3 & 13.19 & 3.46 & 97.37 & 90.93 \\
\hline Average & 13.19 & 3.45 & 97.37 & 90.99 \\
\hline
\end{tabular}

As shown in Table 4.17, the oxygen percentage of recycled PC is decreased from $13.48 \%$ in the original sample. This is explained by the fact that impurities in ABS are left in PC. But the oxygen content of recycled ABS increased from $2.46 \%$ to an average of $3.45 \%$. The only explanation is that this sample of PC has a very low solubility in acetone, and a small amount of the PC on the surface dissolved in acetone together with $\mathrm{ABS}$, and remained in $\mathrm{ABS}$, which contributes to an increased oxygen percentage in recycled ABS. Also because of this, the purities of $\mathrm{PC}$ and ABS are both calculated. Calculated results are listed in Table 4.17. After separation, the purity of PC is increased from $90 \%$ in the original sample to an average purity of $97.37 \%$, and the average purity of the recovered ABS is $90.99 \%$ compared to the original sample of $10 \% \mathrm{ABS}$. 
- $\quad$ PC/PS/ABS Separation

10 grams of plastic mixture with $90 \%$ PC, $5 \%$ PS, and 5\%ABS were taken to perform separation experiments. Oxygen analysis results and calculated purities are shown in Table 4.18.

Table 4.18 Oxygen analysis results and calculated purities of PC and ABS

\begin{tabular}{|c|c|c|c|c|c|}
\hline $\begin{array}{c}\text { No. of } \\
\text { Experiments }\end{array}$ & $\begin{array}{c}\mathrm{O} \% \text { in } \\
\text { Recycled PC }\end{array}$ & $\begin{array}{c}\mathrm{O} \% \text { in } \\
\text { Recycled PS }\end{array}$ & $\begin{array}{c}\mathrm{O} \% \text { in } \\
\text { Recycled } \\
\text { ABS }\end{array}$ & $\begin{array}{c}\text { Purity of } \\
\text { Recycled } \\
\mathrm{PC} \\
(\%)\end{array}$ & $\begin{array}{c}\text { Purity of } \\
\text { Recycled } \\
\text { ABS } \\
(\%)\end{array}$ \\
\hline 1 & 12.80 & 0.91 & 2.52 & 93.83 & 99.46 \\
\hline 2 & 13.40 & 0.85 & 2.49 & 99.27 & 99.73 \\
\hline 3 & 13.42 & 0.82 & 2.79 & 99.46 & 97.00 \\
\hline Average & 13.21 & 0.86 & 2.60 & 97.52 & 98.73 \\
\hline
\end{tabular}

As mentioned in Section 3.3.1, ABS is removed first. For the same reason described in the PC/ABS separation, the percent oxygen of PC is decreased and that of ABS is increased. When calculating the purities of PC and ABS, it is assumed that PS in the mixture is removed completely to simplify the calculation. Therefore, the same purity analysis procedure as described in PC/PS separation is used. As shown in Table 4.18 , an average purity of $97.86 \% \mathrm{PC}$ is obtained from the $90 \% \mathrm{PC}$ in the original sample. The purity of ABS is increased from $5 \%$ in original sample to $98.73 \%$ in recycled ABS. For the same reason described in PC/PS separation, oxygen percentage of recycled PS is reduced, and PS is purified during the separation process. Therefore the purity of PS cannot be predicted by calibration curve. It is also assumed that the purity of PS is increased form $5 \%$ to $100 \%$ by comparing with the original sample. 


\section{Preliminary Economic Analysis}

In this work, a preliminary investigation of the process economics for a separation process of $\mathrm{PC} / \mathrm{PS} / \mathrm{ABS}$ is carried out. This study assumed that $1000 \mathrm{~kg} / \mathrm{day}$ of mixed plastics is to be treated in a batch process. The components of the mixed plastics are $90 \%$ PC, $5 \%$ percent $\mathrm{PS}$, and $5 \%$ percent $\mathrm{ABS}$.

\subsection{Flow diagram and flow table}

Based on the composition of mixed plastics, a separation process was designed operate 340 day/year, two batches per day, and eight hours per batch to separate the mixed plastics. The flow diagram of this process is shown in Figure 5.1.

Since $1000 \mathrm{~kg}$ of mixed plastics which include $90 \%$ PC, $5 \%$ PS, and $5 \%$ ABS is to be treated per day, the amount of solvents and antisolvents needed every day were calculated as follows.

The mixed plastics of Stream 2 in Figure 5.1 are:

$$
\begin{aligned}
& M_{P C}=1000 \mathrm{~kg} / \text { day } \times 90 \%=900 \mathrm{~kg} / \text { day } \\
& M_{P S}=1000 \mathrm{~kg} / \text { day } \times 5 \%=50 \mathrm{~kg} / \text { day } \\
& M_{A B S}=1000 \mathrm{~kg} / \text { day } \times 5 \%=50 \mathrm{~kg} / \text { day }
\end{aligned}
$$

Referring to the optimized experimental conditions in Chapter 4, 1 gram of ABS dissolved in $100 \mathrm{ml}$ acetone, so the amount of acetone in Stream 1 is:

$$
M_{\text {acetone }}=788 \mathrm{~kg} / \mathrm{m}^{3} \times 0.1 \mathrm{~m}^{3} / \mathrm{kg} \times 50 \mathrm{~kg} / \text { day }=3940 \mathrm{~kg} / \text { day }
$$

In Stream 8, water used for washing is:

$$
M_{\text {water }}=500 \mathrm{~kg} / \text { day }
$$

In Stream 9, water used for precipitation is: 


$$
M_{\text {water }}=1000 \mathrm{~kg} / \mathrm{m}^{3} \times 5 \mathrm{~m}^{3} / \text { day }=5000 \mathrm{~kg} / \text { day }
$$

In Stream 10, water used for washing is:

$$
M_{\text {water }}=500 \mathrm{~kg} / \text { day }
$$

Therefore, the total amount of water needed every day is:

$$
M_{\text {total }}=500+5000+500=6000 \mathrm{~kg} / \text { day }
$$

In Stream 19, the amount of cyclohexane used to dissolve PS is:

$$
M_{\text {cyclohexane }}=800 \mathrm{~kg} / \mathrm{m}^{3} \times 0.1 \mathrm{~m}^{3} / \mathrm{kg} \times 50 \mathrm{~kg} / \text { day }=4000 \mathrm{~kg} / \text { day }
$$

In Stream 22, ethanol used for precipitation is:

$$
M_{\text {water }}=785 \mathrm{~kg} / \mathrm{m}^{3} \times 2.5 \mathrm{~m}^{3} / \text { day }=1962.5 \mathrm{~kg} / \text { day }
$$

In Stream 30, ethanol used for washing is:

$$
M_{\text {ethanol }}=196.25 \mathrm{~kg} / \mathrm{day}
$$

In Stream 36, ethanol used for washing is:

$$
M_{\text {ethanol }}=196.25 \mathrm{~kg} / \text { day }
$$

Therefore, the total amount of ethanol used every day is:

$$
M_{\text {total }}=1962.5+196.25+196.25=2355 \mathrm{~kg} / \text { day }
$$

Based on these results, the amount of mixed plastics to be treated, and the flow diagram in Figure 5.1, and the flow table in Table 5.1 were established to show the material balance of each stream. 


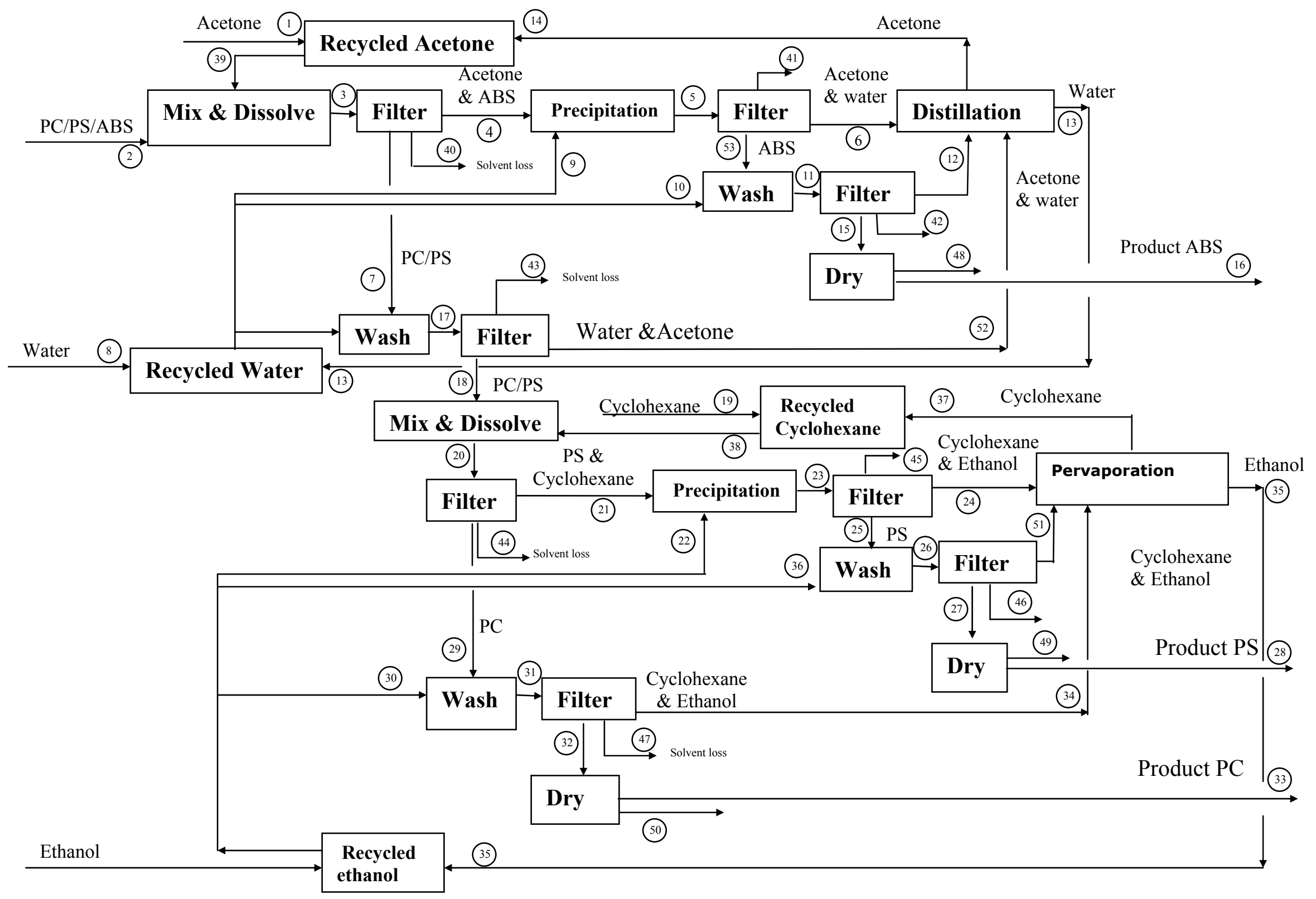

Figure 5.1 Flow diagram of PC/PS/ABS separation 
Table 5.1 Flow table for PC/PS/ABS separation process

\begin{tabular}{|c|c|c|c|c|c|c|c|c|c|c|c|c|c|c|c|}
\hline \multicolumn{2}{|c|}{ Stream No. } & 1 & 2 & 3 & 4 & 5 & 6 & 7 & 8 & 9 & 10 & 11 & 12 & 13 & 14 \\
\hline \multicolumn{2}{|r|}{$\mathbf{T}\left({ }^{\circ} \mathbf{C}\right)$} & 25 & 25 & 25 & 25 & 25 & 25 & 25 & 25 & 25 & 25 & 25 & 25 & 25 & 25 \\
\hline \multirow{8}{*}{$\begin{array}{c}\text { Mass } \\
\text { Flow } \\
(\mathbf{K g} / \mathbf{h})\end{array}$} & PC & 0.0 & 4.1 & 4.1 & 0.0 & 0.0 & 0.0 & 4.1 & 0.0 & 0.0 & 0.0 & 0.0 & 0.0 & 0.0 & 0.0 \\
\hline & PS & 0.0 & 2.1 & 2.1 & 0.0 & 0.0 & 0.0 & 2.1 & 0.0 & 0.0 & 0.0 & 0.0 & 0.0 & 0.0 & 0.0 \\
\hline & ABS & 0.0 & 2.1 & 2.1 & 2.1 & 2.1 & 0.0 & 0.0 & 0.0 & 0.0 & 0.0 & 2.1 & 0.0 & 0.0 & 0.0 \\
\hline & Acetone & 0.0 & 0.0 & 164.2 & 164.2 & 164.2 & 164.2 & 0.0 & 0.0 & 0.0 & 0.0 & 0.0 & 0.0 & 0.0 & 164.2 \\
\hline & Water & 0.0 & 0.0 & 0.0 & 0.0 & 0.0 & 0.0 & 0.0 & 0.0 & 208.3 & 20.8 & 20.8 & 20.8 & 41.7 & 0.0 \\
\hline & Cyclohexane & 0.0 & 0.0 & 0.0 & 0.0 & 0.0 & 0.0 & 0.0 & 0.0 & 0.0 & 0.0 & 0.0 & 0.0 & 0.0 & 0.0 \\
\hline & Ethanol & 0.0 & 0.0 & 0.0 & 0.0 & 0.0 & 0.0 & 0.0 & 0.0 & 0.0 & 0.0 & 0.0 & 0.0 & 0.0 & 0.0 \\
\hline & Total Mass flow & 0.0 & 8.3 & 172.5 & 166.3 & 166.3 & 164.2 & 6.2 & 0.0 & 208.3 & 20.8 & 22.9 & 20.8 & 41.7 & 164.2 \\
\hline
\end{tabular}

Table 5.1 (continued)

\begin{tabular}{|c|c|c|c|c|c|c|c|c|c|c|c|c|c|c|c|}
\hline \multirow{2}{*}{\multicolumn{2}{|c|}{$\begin{array}{c}\text { Stream No. } \\
\mathbf{T}\left({ }^{\circ} \mathbf{C}\right)\end{array}$}} & 15 & 16 & 17 & 18 & 19 & 20 & 21 & 22 & 23 & 24 & 25 & 26 & 27 & 28 \\
\hline & & 25 & 50 & 25 & 25 & 25 & 80 & 80 & 25 & 25 & 25 & 25 & 25 & 25 & 50 \\
\hline \multirow{8}{*}{$\begin{array}{c}\text { Mass } \\
\text { Flow } \\
(\mathbf{K g} / \mathbf{h})\end{array}$} & PC & 0.0 & 0.0 & 4.1 & 4.1 & 0.0 & 4.1 & 0.0 & 0.0 & 0.0 & 0.0 & 0.0 & 0.0 & 0.0 & 0.0 \\
\hline & PS & 0.0 & 0.0 & 2.1 & 2.1 & 0.0 & 2.1 & 2.1 & 0.0 & 2.1 & 0.0 & 2.1 & 2.1 & 2.1 & 2.1 \\
\hline & ABS & 2.1 & 2.1 & 0.0 & 0.0 & 0.0 & 0.0 & 0.0 & 0.0 & 0.0 & 0.0 & 0.0 & 0.0 & 0.0 & 0.0 \\
\hline & Acetone & 0.0 & 0.0 & 0.0 & 0.0 & 0.0 & 0.0 & 0.0 & 0.0 & 0.0 & 0.0 & 0.0 & 0.0 & 0.0 & 0.0 \\
\hline & Water & 0.0 & 0.0 & 20.8 & 0.0 & 0.0 & 0.0 & 0.0 & 0.0 & 0.0 & 0.0 & 0.0 & 0.0 & 0.0 & 0.0 \\
\hline & Cyclohexane & 0.0 & 0.0 & 0.0 & 0.0 & 0.0 & 166.7 & 166.7 & 0.0 & 166.7 & 166.7 & 0.0 & 0.0 & 0.0 & 0.0 \\
\hline & Ethanol & 0.0 & 0.0 & 0.0 & 0.0 & 0.0 & 0.0 & 0.0 & 81.8 & 81.8 & 81.8 & 0.0 & 8.2 & 0.0 & 0.0 \\
\hline & Total Mass flow & 2.1 & 2.1 & 27.0 & 6.2 & 0.0 & 172.9 & 168.8 & 81.8 & 250.6 & 248.5 & 2.1 & 10.3 & 2.1 & 2.1 \\
\hline
\end{tabular}


Table 5.1 (continued)

\begin{tabular}{|c|c|c|c|c|c|c|c|c|c|c|c|c|c|c|c|}
\hline \multicolumn{2}{|c|}{ Stream No. } & 29 & 30 & 31 & 32 & 33 & 34 & 35 & 36 & 37 & 38 & 39 & 40 & 41 & 42 \\
\hline \multicolumn{2}{|r|}{$\mathbf{T}\left({ }^{\circ} \mathbf{C}\right)$} & 25 & 25 & 25 & 25 & 50 & 25 & 25 & 25 & 25 & 25 & 25 & 25 & 25 & 25 \\
\hline \multirow{8}{*}{$\begin{array}{c}\text { Mass } \\
\text { Flow } \\
(\mathbf{K g} / \mathbf{h})\end{array}$} & PC & 4.1 & 0.0 & 4.1 & 4.1 & 4.1 & 0.0 & 0.0 & 0.0 & 0.0 & 0.0 & 0.0 & 0.0 & 0.0 & 0.0 \\
\hline & PS & 0.0 & 0.0 & 0.0 & 0.0 & 0.0 & 0.0 & 0.0 & 0.0 & 0.0 & 0.0 & 0.0 & 0.0 & 0.0 & 0.0 \\
\hline & ABS & 0.0 & 0.0 & 0.0 & 0.0 & 0.0 & 0.0 & 0.0 & 0.0 & 0.0 & 0.0 & 0.0 & 0.0 & 0.0 & 0.0 \\
\hline & Acetone & 0.0 & 0.0 & 0.0 & 0.0 & 0.0 & 0.0 & 0.0 & 0.0 & 0.0 & 0.0 & 164.2 & 0.0 & 0.0 & 0.0 \\
\hline & Water & 0.0 & 0.0 & 0.0 & 0.0 & 0.0 & 0.0 & 0.0 & 0.0 & 0.0 & 0.0 & 0.0 & 0.0 & 0.0 & 0.0 \\
\hline & Cyclohexane & 0.0 & 0.0 & 0.0 & 0.0 & 0.0 & 0.0 & 0.0 & 0.0 & 166.7 & 166.7 & 0.0 & 0.0 & 0.0 & 0.0 \\
\hline & Ethanol & 0.0 & 8.2 & 8.2 & 0.0 & 0.0 & 8.2 & 98.1 & 8.2 & 0.0 & 0.0 & 0.0 & 0.0 & 0.0 & 0.0 \\
\hline & Total Mass flow & 4.1 & 8.2 & 12.3 & 4.1 & 4.1 & 8.2 & 98.2 & 8.2 & 166.7 & 166.7 & 164.2 & 0.0 & 0.0 & 0.0 \\
\hline
\end{tabular}

Table 5.1 (continued)

\begin{tabular}{|c|c|c|c|c|c|c|c|c|c|c|c|c|c|c|}
\hline 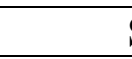 & tream No. & 43 & 44 & 45 & 46 & 47 & 48 & 49 & 50 & 51 & 52 & 53 & 54 & 55 \\
\hline & $\mathbf{T}\left({ }^{\circ} \mathrm{C}\right)$ & 25 & 25 & 25 & 25 & 25 & 25 & 25 & 25 & 25 & 25 & 25 & 25 & 25 \\
\hline & PC & 0.0 & 0.0 & 0.0 & 0.0 & 0.0 & 0.0 & 0.0 & 0.0 & 0.0 & 0.0 & 0.0 & 0.0 & 0.0 \\
\hline & PS & 0.0 & 0.0 & 0.0 & 0.0 & 0.0 & 0.0 & 0.0 & 0.0 & 0.0 & 0.0 & 0.0 & 0.0 & 0.0 \\
\hline & ABS & 0.0 & 0.0 & 0.0 & 0.0 & 0.0 & 0.0 & 0.0 & 0.0 & 0.0 & 0.0 & 2.1 & 0.0 & 0.0 \\
\hline & Acetone & 0.0 & 0.0 & 0.0 & 0.0 & 0.0 & 0.0 & 0.0 & 0.0 & 0.0 & 0.0 & 0.0 & 0.0 & 0.0 \\
\hline $\begin{array}{l}\text { How } \\
(\mathrm{Ka} / \mathrm{h})\end{array}$ & Water & 0.0 & 0.0 & 0.0 & 0.0 & 0.0 & 0.0 & 0.0 & 0.0 & 0.0 & 20.8 & 0.0 & 0.0 & 20.8 \\
\hline & Cyclohexane & 0.0 & 0.0 & 0.0 & 0.0 & 0.0 & 0.0 & 0.0 & 0.0 & 0.0 & 0.0 & 0.0 & 0.0 & 0.0 \\
\hline & Ethanol & 0.0 & 0.0 & 0.0 & 0.0 & 0.0 & 0.0 & 0.0 & 0.0 & 8.2 & 0.0 & 0.0 & 0.0 & 0.0 \\
\hline & Total Mass flow & 0.0 & 0.0 & 0.0 & 0.0 & 0.0 & 0.0 & 0.0 & 0.0 & 8.2 & 20.8 & 2.1 & 0.0 & 20.8 \\
\hline
\end{tabular}




\subsection{Initial raw material cost}

From the calculated amount of solvents and antisolvents in Section 5.1, the initial raw material cost is estimated and listed in Table 5.2. Prices of solvents are quoted from Chemical Market Reporter. It is assumed that for all solvents except water three days supply are initially purchased and stored. These costs are included in the initial fixed capital investment.

Table 5.2 Initial raw material cost

\begin{tabular}{|c|c|c|c|}
\hline Material & Mass flow (kg/day) & Price $(\$ / \mathrm{kg})$ & Year cost $(\$ /$ year $)$ \\
\hline Acetone & 3940 & $\$ 0.389$ & $\$ 4,598$ \\
Ethanol & 2355 & $\$ 0.472$ & $\$ 3,334$ \\
Cyclohexane & 4000 & $\$ 0.476$ & $\$ 5,712$ \\
water & 6000 & $\$ 0.067$ & $\$ 402$ \\
\hline Total cost & \multicolumn{3}{|c|}{$\$ 14,046$} \\
\hline
\end{tabular}

\subsection{Equipment choice and costs}

On the basis of the flow diagram in Figure 5.1, appropriate equipment was selected for each step.

- $\underline{\text { Tanks }}$

Twelve tanks, which are made of stainless steel 304, were selected for the whole process. The volume of tanks depends on the total volume of solvents and polymers. It was assumed that the tanks are to be half filled. Walas's Chemical Process Equipment [1988] provided some API Standard tanks and the formula to calculate the purchased cost of these tanks.

The equation used to estimate purchased cost of these tanks is:

$$
C=2.4 \exp \left[2.631+1.3673(\ln V)-0.06309(\ln V)^{2}\right] \$
$$

Where, 


$$
1300<V<21,000 \mathrm{gal} V \text { is the volume of tank }
$$

The chosen tanks and their purchased equipment cost are listed in Table 5.3.

Table 5.3 Sizes and costs of tanks

\begin{tabular}{|c|r|r|r|r|r|r|}
\hline $\begin{array}{c}\text { No. of } \\
\text { tanks }\end{array}$ & $\begin{array}{c}\text { Calculated } \\
\text { volume (gallon) }\end{array}$ & $\begin{array}{c}\text { Capacity } \\
\text { (gallon) }\end{array}$ & $\begin{array}{c}\text { Diameter } \\
\text { (inch) }\end{array}$ & $\begin{array}{c}\text { Length } \\
\text { (ft-in.) }\end{array}$ & $\begin{array}{c}\text { Thickness } \\
\text { (inch) }\end{array}$ & $\begin{array}{c}\text { Purchased } \\
\text { equipment Cost(\$) }\end{array}$ \\
\hline 1 & 1571.87 & 1500 & 64 & $9-0$ & $3 / 16$ & $\$ 7,276$ \\
2 & 1599.72 & 1500 & 64 & $9-0$ & $3 / 16$ & $\$ 7,276$ \\
3 & 2654.48 & 3000 & 64 & $18-9$ & $3 / 16$ & $\$ 7,511$ \\
4 & 1994.03 & 2000 & 64 & $12-0$ & $3 / 16$ & $\$ 7,447$ \\
5 & 144.77 & 280 & 42 & $4-0$ & $3 / 16$ & $\$ 4,779$ \\
6 & 370.91 & 550 & 48 & $6-0$ & $3 / 16$ & $\$ 6,000$ \\
7 & 78.73 & 280 & 42 & $4-0$ & $3 / 16$ & $\$ 4,779$ \\
8 & 292.18 & 280 & 48 & $4-0$ & $3 / 16$ & $\$ 4,779$ \\
9 & 1320.90 & 1500 & 64 & $9-0$ & $3 / 16$ & $\$ 7,276$ \\
10 & 1585.08 & 1500 & 64 & $9-0$ & $3 / 16$ & $\$ 7,276$ \\
11 & 792.54 & 1000 & 48 & $12-0$ & $3 / 16$ & $\$ 6,873$ \\
12 & 1320.90 & 1500 & 64 & $9-0$ & $3 / 16$ & $\$ 7,276$ \\
\hline Total cost & \multicolumn{7}{|c|}{} \\
\hline
\end{tabular}

- $\underline{\text { Filters }}$

Four stationary screen separators were selected for the filtration process. In Figure 5.1, Filter No. 1 will be used for stream 3 and 17. Filter No. 2 is used for stream 20 and 31, and Filter No. 3 is used for stream 5 and 11. And Filter No. 4 is used for stream 23 and 26. Assuming the average bulk density of polymer is $1000 \mathrm{~kg} / \mathrm{m}^{3}$, the volume of polymer to be treated in the filtration process per batch can be calculated as follows:

For Filter No.1, the volume of polymers to be treated is:

$$
475 \mathrm{~kg} \div 1000 \mathrm{~kg} / \mathrm{m}^{3}=0.475 \mathrm{~m}^{3}=16.77 \mathrm{ft}^{3}
$$

For Filter No.2, the volume of polymers to be treated is:

$$
450 \mathrm{~kg} \div 1000 \mathrm{~kg} / \mathrm{m}^{3}=0.45 \mathrm{~m}^{3}=15.89 \mathrm{ft}^{3}
$$

For Filter No.3, the volume of polymers to be treated is: 


$$
25 \mathrm{~kg} \div 1000 \mathrm{~kg} / \mathrm{m}^{3}=0.025 \mathrm{~m}^{3}=0.883 \mathrm{ft}^{3}
$$

For Filter No.4, the volume of polymers to be treated is:

$$
25 \mathrm{~kg} \div 1000 \mathrm{~kg} / \mathrm{m}^{3}=0.025 \mathrm{~m}^{3}=0.883 \mathrm{ft}^{3}
$$

Assuming the depth of loading for each filter is 3 in., the filtration areas for the four different filters were obtained from the above results. Based on the filtration area and the size of polymer to be filtered, the sizes of screen for filters were decided and listed in Table 5.4. Also, the purchased equipment cost was evaluated by www.matche.com.

Table 5.4 Size and costs of vibrating screen separator

\begin{tabular}{|c|c|c|c|c|c|}
\hline $\begin{array}{c}\text { No. of } \\
\text { filters }\end{array}$ & $\begin{array}{c}\text { Mesh of } \\
\text { screen }\end{array}$ & $\begin{array}{c}\text { Clear } \\
\text { opening(in.) }\end{array}$ & $\begin{array}{c}\text { Wire } \\
\text { diameter(in.) }\end{array}$ & $\begin{array}{c}\text { Area of } \\
\text { filtration }\left(\mathrm{ft}^{2}\right)\end{array}$ & $\begin{array}{c}\text { Purchased } \\
\text { equipment cost }(\$)\end{array}$ \\
\hline 1 & 12 & 0.055 & 0.028 & 68 & $\$ 17,600$ \\
2 & 12 & 0.055 & 0.028 & 64 & $\$ 17,200$ \\
3 & 12 & 0.055 & 0.028 & 4 & $\$ 5,300$ \\
4 & 12 & 0.055 & 0.028 & 4 & $\$ 5,300$ \\
\hline Total cost & \multicolumn{5}{|l}{} \\
\hline
\end{tabular}

- Dryer

Vacuum tray dryers are selected for three different polymers because of the lower working temperature. T he amounts of each polymer to be treated in each batch are 450 $\mathrm{kg}$ PC, $25 \mathrm{~kg}$ PS and $25 \mathrm{~kg}$ ABS. Dryers are selected from Walas's Chemical Process Equipment [1988] according to the capacities listed in Table 5.5. In Table 5.5, four dryers are used for $450 \mathrm{~kg}$ PC, two dryer are selected for $25 \mathrm{~kg}$ PS and $25 \mathrm{~kg}$ ABS. Costs of dryers were estimated by $\underline{w w w . m a t c h e . c o m}$. 
Table 5.5 Size and costs of Vacuum tray dryers

\begin{tabular}{|c|c|c|c|c|c|c|c|}
\hline $\begin{array}{c}\text { Capacity } \\
(\mathrm{kg} / \mathrm{hr})\end{array}$ & $\begin{array}{c}\text { No. } \\
\text { of } \\
\text { trays }\end{array}$ & $\begin{array}{c}\text { Tray } \\
\text { spacing } \\
(\mathrm{cm})\end{array}$ & $\begin{array}{c}\text { Tray size } \\
(\mathrm{cm})\end{array}$ & $\begin{array}{c}\text { Depth of } \\
\text { loading } \\
(\mathrm{cm})\end{array}$ & $\begin{array}{c}\text { No. of } \\
\text { dryer }\end{array}$ & $\begin{array}{c}\text { Unit } \\
\text { Cost } \\
(\$)\end{array}$ & $\begin{array}{c}\text { Purchased } \\
\text { equipment } \\
\text { Cost }(\$)\end{array}$ \\
\hline 122 & 16 & 43 & $91.4 \times 104$ & 7.0 & 4 & 7,100 & $\$ 28,400$ \\
27.7 & 24 & 43 & $85 \times 98$ & 4 & 2 & 6,700 & $\$ 13,400$ \\
\hline Total cost & \multicolumn{10}{|c}{} \\
\hline
\end{tabular}

\section{- Distillation tower}

A distillation tower was designed to separate acetone from water. A design of the distillation tower is shown in Figure 5.2. This column will be operated continuously using feed tanks to regulate the flow from the batch process.

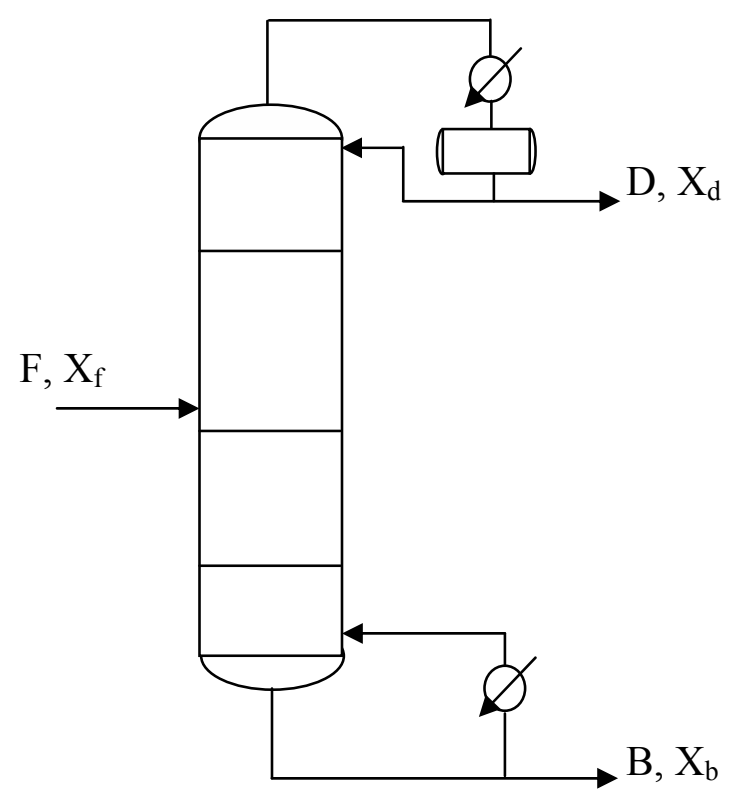

Figure 5.2 The schematic diagram of distillation tower

(1) Number of trays

As calculated in section 5.1, the amount of acetone to be treated per day is:

$$
M_{\text {acetone }}=3940 \mathrm{~kg} / \text { day }
$$

And water to be treated every day is: 


$$
M_{\text {water }}=6000 \mathrm{~kg} / \mathrm{day}
$$

Assuming that the mixture of water and acetone is separated with the distillation tower in 24 hours per day, then, the flow rates of acetone and water are:

$$
\begin{aligned}
& M_{\text {acetone }}=3940 \mathrm{~kg} / \text { day } \div 24 \mathrm{hr} / \text { day }=164.17 \mathrm{~kg} / \mathrm{hr}=2831 \mathrm{~mol} / \mathrm{hr} \\
& M_{\text {water }}=6000 \mathrm{~kg} / \text { day } \div 24 \mathrm{hr} / \text { day }=250 \mathrm{~kg} / \mathrm{hr}=13889 \mathrm{~mol} / \mathrm{hr}
\end{aligned}
$$

Hence

$$
\begin{aligned}
& F=2831+13889=16720(\mathrm{~mol} / \mathrm{hr}) \\
& X_{f}=\frac{2381}{16720}=0.142
\end{aligned}
$$

It is assumed that the purity of recovered acetone is $99 \%$ (weight percent), and the recovery of acetone is $99 \%$. Then:

$$
X_{d}=\frac{0.99 / 58}{0.99 / 58+0.01 / 18}=0.968
$$

By making material balances, the following equations are obtained:

$$
\begin{aligned}
& F=D+B \\
& F X_{f}=D X_{d}+B X_{b} \\
& D X_{d} / F X_{f}=99 \%
\end{aligned}
$$

Substituting $F=16720 \mathrm{~mol} / \mathrm{hr}, X_{f}=0.142 X_{d}=0.968$ into the above equations:

$$
\begin{aligned}
& 16720=D+B \\
& 16720 \times 0.142=D \times 0.968+B X_{b} \\
& D \times 0.968 / 16720 \times 0.142=99 \%
\end{aligned}
$$

By solving these equations, the following results are obtained: 


$$
\left\{\begin{array}{l}
F=16720(\mathrm{~mol} / \mathrm{hr}) \\
D=2428(\mathrm{~mol} / \mathrm{hr}) \\
B=14292(\mathrm{~mol} / \mathrm{hr})
\end{array}, \quad\left\{\begin{array}{l}
X_{f}=0.142 \\
X_{d}=0.968 \\
X_{b}=0.002
\end{array}\right.\right.
$$

Considering the thermal conditions of feed, the feed factor $q$ is about 1.2. So the slope of $q$ - line is:

$$
\text { Slope }=\frac{q}{q-1}=\frac{1.2}{1.2-1}=6
$$

Then the equation of the $q$ - line is:

$$
Y=\frac{q}{q-1} X+\frac{1}{q-1} X_{f}
$$

Based on the above information, the minimum reflux ratio $\mathrm{R}_{\min }$ is obtained from Figure 5.3.

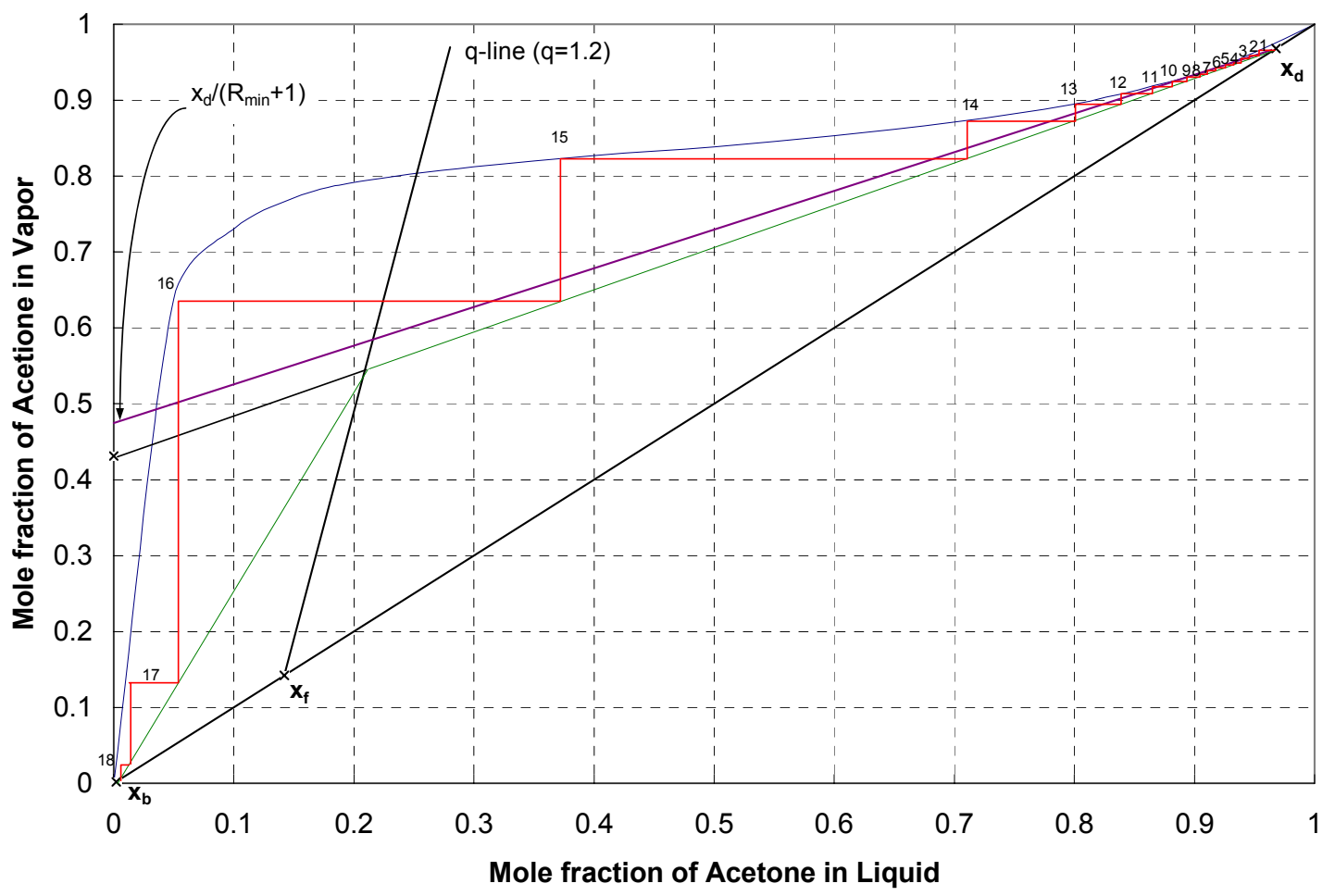

Figure 5.3 Equilibrium stage requirements for the separation of water and acetone 
From Figure 5.3,

$$
\frac{X_{d}}{R_{\text {min }}+1}=0.475
$$

Hence

$$
R_{\min }=1.04
$$

It is assumed that $R=1.2 R_{\min }$. So the reflux ratio is

$$
R=1.25
$$

Thus the two operating lines were obtained, and the theoretical tray numbers was estimated as:

$$
\mathrm{N}_{\text {theoretical }}=18
$$

From Walas [1988], using an experimental tray efficiency $\varepsilon=0.91$, then the actual number of trays is:

$$
N_{\text {actual }}=\frac{N_{\text {theoretical }}}{\varepsilon} \frac{18}{0.91}=20
$$

(2) Diameter of column

A long -established empirical correction shows that the maximum permissible vapor velocity is proportional to $\sqrt{\left(\rho_{L}-\rho_{v}\right) / \rho_{v}}$. Thus

$$
\mathrm{U}_{\mathrm{c}}=\mathrm{K}_{\mathrm{v}} \sqrt{\frac{\rho_{\mathrm{L}}-\rho_{\mathrm{V}}}{\rho_{\mathrm{V}}}}
$$

Where $U_{c}=$ Maximum permissible velocity based on bubbling area

$$
K_{v}=\text { empirical coefficient }
$$

Values of $K_{v}$ for use with this equation are shown in Fig. 5.4. 
Physical properties of acetone: molecular weight 58, normal boiling point is $56.5^{\circ} \mathrm{C}$, and the density of vapor is:

$$
\rho_{V}=\frac{58 \times 273}{22.4 \times(273+56.5)}=2.145 \mathrm{~kg} / \mathrm{m}^{3}
$$

From Perry's Chemical Engineer's Handbook [1984], the density of liquid acetone is:

$$
\rho_{l}=0.27728 \times 0.25761^{-\left(1-\frac{329.5}{508.20}\right)^{0.29903}}=747.9 \mathrm{~kg} / \mathrm{m}^{3}
$$

Since $R=1.25$, then

$$
\begin{aligned}
& L=R D=1.25 \times 2428=3035 \mathrm{~mol} / \mathrm{hr} \\
& V=L+D=3035+2428=5463 \mathrm{~mol} / \mathrm{hr}
\end{aligned}
$$

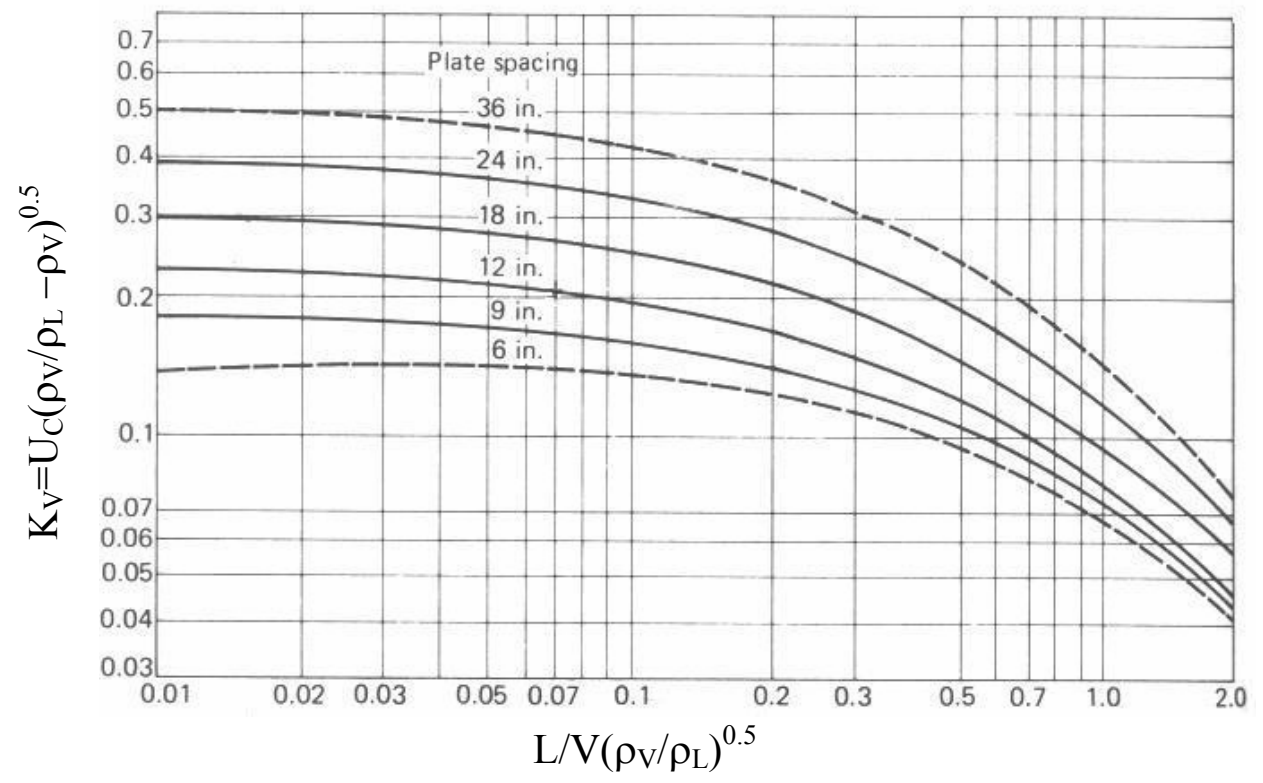

Figure 5.4 Values of $\boldsymbol{K}_{v}$ at flooding conditions for sieve plates (McCabe et al. [1993])

The abscissa in Fig. 5.4 is:

$$
\frac{L}{V}\left(\frac{\rho_{v}}{\rho_{l}}\right)^{1 / 2}=\frac{3035}{5463}\left(\frac{2.145}{747.9}\right)^{1 / 2}=0.0298
$$

For 6-inch plate spacing, 


$$
K_{v}=U_{c}\left(\frac{\rho_{v}}{\rho_{v}-\rho_{l}}\right)^{1 / 2} \mathrm{ft} / \mathrm{sec}=0.14
$$

Therefore

$$
U_{c}=2.611 \mathrm{ft} / \mathrm{sec}=0.796 \mathrm{~m} / \mathrm{s}
$$

So the vapor flow rate is

$$
V=\frac{5463 \mathrm{~mol} / \mathrm{hr} \times 58 \times 10^{-3} \mathrm{~kg} / \mathrm{mol}}{3600 \mathrm{~s} / \mathrm{hr} \times 2.145 \mathrm{~kg} / \mathrm{m}^{3}}=0.041 \mathrm{~m}^{3} / \mathrm{s}
$$

And the bubbling area of the column is

$$
\text { Bubbling Area }=\frac{0.041 \mathrm{~m}^{3} / \mathrm{s}}{0.796 \mathrm{~m} / \mathrm{s}}=0.052 \mathrm{~m}^{2}
$$

Assuming the bubbling area is $80 \%$, so the cross section area of the column is

$$
\text { Column Area }=0.052 / 0.8=0.065 m^{2}
$$

Finally, the diameter of the column is

$$
D_{C}=\left(\frac{4 \times 0.065}{3.14}\right)^{0.5}=0.288 m=0.95 f t
$$

Based on the above information, the size and cost of designed distillation tower is listed in Table 5.6. Cost evaluation is provided by Turton et al.[2002].

Table 5.6 Size and cost of distillation tower

\begin{tabular}{|c|c|c|c|c|c|c|c|}
\hline Tower & $\begin{array}{c}\text { Tower } \\
\text { description }\end{array}$ & $\begin{array}{c}\text { Tower } \\
\text { MOC }\end{array}$ & $\begin{array}{c}\text { No. } \\
\text { of } \\
\text { trays }\end{array}$ & $\begin{array}{c}\text { Tray } \\
\text { spacing } \\
\text { (in.) }\end{array}$ & $\begin{array}{c}\text { Height } \\
(\mathrm{ft})\end{array}$ & $\begin{array}{c}\text { Diameter } \\
(\mathrm{ft})\end{array}$ & $\begin{array}{c}\text { Purchased } \\
\text { equipment } \\
\text { Cost }\end{array}$ \\
\hline 1 & $\begin{array}{c}20 \text { carbon } \\
\text { steel sieve } \\
\text { trays }\end{array}$ & $\begin{array}{c}\text { Carbon } \\
\text { steel }\end{array}$ & 20 & 6 & 12 & 1.4 & $\$ 18,300$ \\
\hline
\end{tabular}




\section{- $\underline{\text { Condenser }}$}

A simple tubular condenser was designed to liquefy acetone vapor using cooling water as coolant.

An energy balance goes:

$$
\lambda V=u A \Delta T
$$

Here,

$\lambda=130 \mathrm{cal} / \mathrm{g}$, is the latent heat of vaporization of acetone

$V=5463 \mathrm{~mol} / \mathrm{hr}$, is the vapor flow rate in the rectifying section

$\Delta T=40-25=15^{0} \mathrm{C}$, is assumed temperature rise of cooling water

$A$, is the heat exchange area

$u=1700 \mathrm{w} / \mathrm{m}^{2} \cdot{ }^{0} \mathrm{C}$, is overall heat transfer coefficient for water condenser

Substituting these data into the Equation (5.49),

$$
\frac{130 \mathrm{cal} / \mathrm{g} \times 4.18 \mathrm{~J} / \mathrm{cal} \times 5463 \mathrm{~mol} / \mathrm{hr} \times 58 \mathrm{~g} / \mathrm{mol}}{3600 \mathrm{~s} / \mathrm{hr}}=1700 \mathrm{w} / \mathrm{m}^{2} \cdot{ }^{0} \mathrm{C} \times A \times 15^{0} \mathrm{C}
$$

Hence

$$
A=1.87 m^{2}
$$

- $\quad \underline{\text { Reboiler }}$

Steam is used as the heating medium for the economy analysis. By making energy balance on the reboiler, the following equation was obtained:

$$
\lambda_{w} \bar{V}=u A \Delta T
$$

Here,

$$
\begin{aligned}
& \lambda_{w}=540 \mathrm{cal} / \mathrm{g}, \text { is the latent heat of vaporization of water } \\
& u=6,000 \mathrm{w} / \mathrm{m}^{2} \cdot{ }^{0} \mathrm{C}, \text { is the overall heat -transfer coefficient for the reboiler }
\end{aligned}
$$


$\Delta T=20^{\circ} \mathrm{C}$, is the temperature fall of steam

From Figure 5.3, the slope of operating line in the stripping section is:

$$
\text { slope }=\frac{\bar{L}}{\bar{V}}=\frac{0.48-0.002}{0.2-0.002}=2.41
$$

Because $B=\bar{L}-\bar{V}=14292 \mathrm{~mol} / \mathrm{hr}$

Therefore

$$
\bar{V}=10136 \mathrm{~mol} / \mathrm{hr}
$$

Substituting these data into the Equation (5.52),

$$
\frac{540 \mathrm{cal} / \mathrm{g} \times 4.18 \mathrm{~J} / \mathrm{cal} \times 10136 \mathrm{~mol} / \mathrm{hr} \times 18 \mathrm{~g} / \mathrm{mol}}{3600 \mathrm{~s} / \mathrm{hr}}=6000 \mathrm{w} / \mathrm{m}^{2} \cdot{ }^{0} \mathrm{C} \times A \times 20^{0} \mathrm{C}
$$

Hence

$$
A=0.95 m^{2}
$$

Based on this heat exchange area, a double pipe heat exchanger was chosen, and the size and costs of the reboiler are listed in Table 5.7.

\section{Table 5.7 Size and cost of heat exchanger}

\begin{tabular}{|ccccccc|}
\hline $\begin{array}{c}\text { Heat } \\
\text { exchanger }\end{array}$ & $\begin{array}{c}\text { Type of } \\
\text { exchanger } \\
\text { Double }\end{array}$ & $\begin{array}{c}\text { Tube } \\
\text { pressure } \\
\text { (barg) }\end{array}$ & MOC & $\begin{array}{c}\text { Area } \\
\left(\mathrm{m}^{2}\right)\end{array}$ & $\begin{array}{c}\text { Purchased } \\
\text { equipment } \\
\text { cost }(\$)\end{array}$ & $\begin{array}{c}\text { Annual } \\
\text { utility } \\
\text { cost }(\$)\end{array}$ \\
1 & $\begin{array}{c}\text { pipe } \\
\text { Double } \\
\text { pipe }\end{array}$ & 2 & $\begin{array}{c}\text { Stainless steel } \\
\text { /carbon steel }\end{array}$ & 1.87 & 2,600 & 497 \\
& 2 & $\begin{array}{c}\text { Stainless steel } \\
\text { /carbon steel }\end{array}$ & 1.00 & 2,210 & 20,398 \\
\hline
\end{tabular}

- $\quad \underline{\text { Pumps }}$

Six centrifugal pumps were chosen for the whole process as shown in Table 5.8. 
Table 5.8 Pump costs

\begin{tabular}{|cccccc|}
\hline $\begin{array}{c}\text { Able Pump } \\
\text { type }\end{array}$ & $\begin{array}{c}\text { No. } \\
\text { of } \\
\text { pump }\end{array}$ & $\begin{array}{c}\text { Power } \\
\text { (horsepower) }\end{array}$ & MOC & $\begin{array}{c}\text { Purchased } \\
\text { equipment cost }\end{array}$ & $\begin{array}{c}\text { Annual } \\
\text { utility } \\
\text { cost }\end{array}$ \\
Centrifugal & 6 & 1.4 & $\begin{array}{c}\text { Carbon } \\
\text { steel }\end{array}$ & $\$ 2,460$ & $\$ 618$ \\
Total cost & & & & $\$ 14,760$ & $\$ 3,708$ \\
\hline
\end{tabular}

The purchased equipment costs and annual utility costs for distillation tower, heat exchanger and pumps are quoted from Turton et al. [2002].

\section{- Pervaporation equipment}

The separation of organic solvent mixtures is the least developed application of pervaporation. Therefore, it is difficult to find information about equipment cost evaluation. But, in principle, pervaporation could be used as substitute or supplement to distillation process with lower cost and energy savings. This is definitely true for the separation of azeotropes and close boiling-point liquids, which are difficult to separate with conventional distillation techniques. So in this work, it was assumed that the cost of pervaporation equipment for cyclohexane/ethanol separation is at most the same as the cost of distillation tower discussed above. So, the purchased cost of this equipment is also $\$ 18,300$. The main utility of pervaporation process is the energy cost to evaporate cyclohexane and ethanol. Therefore, the annual utility of this equipment is roughly estimated as follows:

The amount of ethanol to be treated everyday is:

$$
M=2355 \mathrm{~kg} / \text { day }=2.13 \times 10^{3} \mathrm{~mol} / \mathrm{hr}
$$

Energy balances give the energy required to evaporate this amount of ethanol:

$$
M C_{p} \Delta T=2.13 \times 10^{3} \mathrm{~mol} / \mathrm{hr} \times 148.27 \mathrm{~J} / \mathrm{mol} \cdot \mathrm{K} \times(351-298) \mathrm{K}=16.7 \mathrm{MJ} / \mathrm{hr}
$$




$$
\lambda M=39.40 \mathrm{KJ} / \mathrm{mol} \times 2.13 \times 10^{3} \mathrm{~mol} / \mathrm{hr}=83.9 \mathrm{MJ} / \mathrm{hr}
$$

The energy required for ethanol in a year is:

$$
(16.7+83.9) M J / m o l \times 24 h r / d a y \times 340 d a y / y r=821 G J / y r
$$

Heated by low-pressure steam, the cost is:

$$
6.08 \$ / G J \times 821 G J / y r=4,991 \$ / y r
$$

For $4000 \mathrm{~kg}$ cyclohexane treated per day, the energy balances give:

$$
\begin{gathered}
M C_{p} \Delta T=1.98 \times 10^{3} \mathrm{~mol} / \mathrm{hr} \times 162.07 \mathrm{~J} / \mathrm{mol} \cdot \mathrm{K} \times(353-298) \mathrm{K}=17.6 \mathrm{MJ} / \mathrm{hr} \\
\lambda M=29.89 \mathrm{KJ} / \mathrm{mol} \times 1.98 \times 10^{3} \mathrm{~mol} / \mathrm{hr}=59.2 \mathrm{MJ} / \mathrm{hr}
\end{gathered}
$$

The energy cost required for cyclohexane in a year is:

$$
(17.6+59.2) M J / m o l \times 24 h r / d a y \times 340 d a y / y r \times 6.08 \$ / G J=3,810 \$ / y r
$$

So the total annual utility cost for pervaporation is:

$$
4,991+3,810=8,801 \$ / y r
$$

\subsection{Capital cost}

Referring to Turton et al. [2002], the Lang Factor method was used to estimate the capital cost of the whole process. The total cost is determined by multiplying the total purchased cost for all the major items of equipment by a constant. The constant multiplier is called the Lang Factor $\left(F_{\text {lang }}\right)$.

The capital cost calculation is determined by using the following equation

$$
C_{T M}=F_{\text {Lang }} \sum_{i=1}^{n} C_{p, i}
$$

Where, $C_{T M}$ is the capital cost (total Module) of the process

$C_{p, i}$ is the purchased cost for the major equipment units 
$n \quad$ is the total number of individual units

$F_{\text {lang }}$ is the Lang factor

For a solid-fluid processing plant, $F_{\text {lang }}=3.63$. The purchased equipment cost was summarized in Table 5.9.

Table 5.9 Purchased equipment costs

\begin{tabular}{|l|r|}
\hline Equipment & Purchased equipment cost \\
\hline Tank (12 units) & $\$ 78,553$ \\
Filter (4 units) & $\$ 45,400$ \\
Dryer (6 units) & $\$ 41,800$ \\
Distillation tower (1 unit) & $\$ 18,300$ \\
Condenser (1 unit) & $\$ 2,600$ \\
Reboiler (1 unit) & $\$ 2,210$ \\
Pump (6 units) & $\$ 14,760$ \\
Pervaporation equipment (1 unit) & $\$ 20,700$ \\
\hline Total & $\$ 221,903$ \\
\hline
\end{tabular}

Therefore, the capital cost $\left(F C I\right.$ or $\left.C_{T M}\right)$ including the initial raw material cost is:

$$
C_{T M}=23,133+3.63 \times \$ 221,903=\$ 828,641
$$

Or,

$$
P=\$ 828,641
$$

The annuity $\mathrm{A}$ is obtained by equation

$$
\frac{A}{P}=\frac{i(1+i)^{10}}{(1+i)^{10}-1}=\frac{0.08(1+0.08)^{10}}{(1+0.08)^{10}-1}=0.149
$$

Hence,

$$
A=\$ 123,468 / \mathrm{yr}
$$




\subsection{Cost of operating labor}

The operating labor requirement for this work is given by equation provided by Turton [2002]:

$$
N_{O L}=\left(6.29+31.7 P^{2}+0.23 N_{n p}\right)^{0.5}
$$

Where, $N_{O L}$ is the number of operators per shift

$P \quad$ is the number of processing steps involving the handling of particular solids $N_{n p}=\Sigma$ Equipment $\quad$ such as compressors, towers, reactors, heaters, exchangers

For the process considered in this work, $P$ is $1, N_{n p}=10$. Then the number of operators required per shift is:

$$
N_{O L}=\left(6.29+31.7 \times 1^{2}+0.23 \times 10\right)^{0.5}=6.35
$$

It is assumed that the facility operates 2 eight-hour shifts per day, 340 days per year. This requires (340 days/year $\times 2$ shifts/day) 680 shifts per year. Each operator is assumed to work 240 shifts per year ( 5 shifts per week and 48 weeks per year, with 2 weeks sick leave and 2 weeks vacation). The number of operators needed to provide this number of shifts is [(680 shifts/year) / (240shifts/operator/year)] about 3 operators. Then,

$$
\text { Operating Labor }=3 \times 6.35 \approx 19
$$

Assume a single operator is paid $\$ 12 / \mathrm{hr}$ for a 2000 -hours year, there is one supervisor per shift, who is paid $\$ 18 / \mathrm{hr}$, and then the operation labor costs are:

$$
\text { Operating labor costs }=17 \times 12 \times 2000+2 \times 18 \times 2000=\$ 480,000 / y r
$$




\subsection{Calculation of utilities}

Based on data in section 5.3, a utility summary for all the equipment is given in Table 5.10.

Table 5.10 Summary of the utility costs for the equipment

\begin{tabular}{|l|r|}
\hline Equipment & Annual Utility cost \\
\hline Dryer & $\$ 4,180$ \\
Condenser & $\$ 497$ \\
Reboiler & $\$ 20,398$ \\
pump & $\$ 3,708$ \\
Pervaporation equipment & $\$ 8,801$ \\
\hline Total & $\$ 37,593$ \\
\hline
\end{tabular}

The total utilities for the whole process is

$$
\text { Total utilities }=\$ 37,593 / \mathrm{yr}
$$

\subsection{Cost of manufacturing}

Quoted from Turton et al. [2002], the cost of manufacturing, COM, can be determined by equation as follow:

$$
C O M=0.180 C_{T M}+C_{O L}+\left(C_{U T}+C_{W T}+C_{R W}\right)
$$

The following cost information were already obtained and listed below:

$\begin{array}{ll}\text { Fixed capital investment } C_{T M} & \$ 123,468 / \mathrm{yr} \\ \text { Raw material cost } C_{R M} & 0 \\ \text { Utilities } C_{U T} & \$ 37,593 / \mathrm{yr} \\ \text { Cost of operating labor } C_{O L} & \$ 480,000 / \mathrm{yr} \\ \text { Cost of waste treatment } C_{W T} & 0\end{array}$


The cost of waste treatment is considered zero because the cost evaluation is based on the assumption of no solvent loss. Therefore, the total manufacturing cost is:

$$
\begin{aligned}
& C O M=0.180 \times 123,468+480,000+37,593 \\
& C O M=\$ 0.540 \times 10^{6} / y r
\end{aligned}
$$

According to the total manufacturing cost, the selling price required to breakdown is:

$$
\$ 0.540 \times 10^{6} / y r \div 340 \text { day } / y r \div 1000 \mathrm{~kg} / \text { day } \div 2.2 \mathrm{lb} / \mathrm{kg}=\$ 0.72 / \mathrm{lb}
$$

Therefore, this result shows that solvent separation of $1000 \mathrm{~kg} /$ day mixed plastics is expensive.

Same economic analyses were carried out for $10,000 \mathrm{~kg} /$ day. The results are listed below. It was assumed that the same labor force would process $10,000 \mathrm{~kg} /$ day as was estimated for the $1,000 \mathrm{~kg} /$ day case.

Table 5. 11 Equipments and costs for $10,000 \mathrm{~kg} /$ day plastic mixtures

\begin{tabular}{|l|r|r|}
\hline Equipment & Purchased equipment cost & Annual utility cost \\
\hline Tank (12 units) & $\$ 246,800$ & $\mathrm{NA}$ \\
\hline Filter (4 units) & $\$ 128,500$ & $\mathrm{NA}$ \\
\hline Dryer (6 units) & $\$ 112,600$ & $\$ 11,260$ \\
\hline Distillation tower (1 unit) & $\$ 18,300$ & $\mathrm{NA}$ \\
\hline Condenser (1 unit) & $\$ 6,580$ & $\$ 4,970$ \\
\hline Reboiler (1 unit) & $\$ 3,700$ & $\$ 203,980$ \\
\hline Pump (6 units) & $\$ 24,072$ & $\$ 37,080$ \\
\hline Pervaporation equipment (1 unit) & $\$ 18,300$ & $\$ 88,010$ \\
\hline Total & $\$ 558,852$ & $\$ 345,300$ \\
\hline
\end{tabular}

And the manufacturing cost is $C O M=\$ 0.886 \times 10^{6} / y r$, the price required for breakeven is $\$ 0.12 / \mathrm{lb}$. This result shows that the solvent-based separation of mixed plastics is economically feasible if the throughput is $10,000 \mathrm{~kg} /$ day. But, this data is optimistic because the current economic analysis is based on the best case, namely that there is no solvent loss in the whole process. 


\section{Conclusions}

1. Plastic samples were obtained from obsolete computers. By identifying the plastics samples using FTIR, it was found that PC, PS, and ABS are the three most prominent types of plastics in EOL computer. Therefore, the research work focused on the separation of these three polymers.

2. A chemical process was developed to separate binary mixtures of PC/PS, PC/ABS, and a ternary mixture of PC/PS/ABS. Investigations were carried out to find the appropriate solvents for the separation experiments. Cyclohexane was chosen to dissolve PS. Acetone was chosen to be the solvent for ABS. Water and ethanol act as antisolvents for these solvents respectively.

3. Optimized experimental conditions were investigated. 1 gram of PS was dissolved in $100 \mathrm{ml}$ of cyclohexane at its boiling point. 1 gram of ABS was dissolved in $100 \mathrm{ml}$ of acetone at room temperature. The volume of solvents is only a function of weight of PS and ABS in the mixture. The volume ratios of solvents and antisolvents used are acetone/water $=1 / 1$, and cyclohexane/ethanol $=2 / 1$. The separated polymers are dried for one hour in a vacuum oven at a pressure of $200 \mathrm{mmHg}$ and temperature $50^{\circ} \mathrm{C}$. Under these conditions, about $0.13 \mathrm{wt} \%$ of solvents are recovered during the drying process.

4. Elemental analysis (EA) was used to measure the oxygen percent of recovered polymer. Based on the EA data, calibration curves of $\mathrm{PC} / \mathrm{PS}$, and $\mathrm{PC} / \mathrm{ABS}$ were obtained and used to predict the purities of recovered polymers. Material balances of calibration curve experiments showed an average recovery of $96.8 \%$. Two linear 
equations were obtained between oxygen and PC composition in the mixture of $\mathrm{PC} / \mathrm{PS}$, and PC/ABS respectively.

5. Separation experiments were carried out with mixtures of $\mathrm{PC} / \mathrm{PS}=9 / 1, \mathrm{PC} / \mathrm{ABS}=9 / 1$ and $\mathrm{PC} / \mathrm{PS} / \mathrm{ABS}=9 / 0.5 / 0.5$. Material and oxygen balances performed for all separation experiments showed that $98.06 \%$ of material and $97.17 \%$ of oxygen are recovered. These results show good material balance closure.

6. For a binary mixture of PC and PS with $90 \% \mathrm{PC}$ and $10 \%$ PS, the purity of recovered PC was $97.60 \%$. PS was purified during the separation process compared with the original sample.

7. For a binary mixture of $\mathrm{PC}$ and $\mathrm{ABS}$, the purity of $\mathrm{PC}$ is increased from $90 \%$ in the original sample to an average purity of $97.37 \%$, and an average purity of $90.99 \%$ in recovered $\mathrm{ABS}$ was reported by comparing with the original sample of $10 \% \mathrm{ABS}$.

8. For a ternary mixture of $\mathrm{PC}$, PS, and ABS, an average purity of $97.86 \% \mathrm{PC}$ is obtained from the $90 \%$ PC in the original sample. The purity of ABS is increased from $5 \%$ in original sample to $98.73 \%$ in recycled ABS. The purity of PS was assumed to increase form $5 \%$ to $100 \%$.

9. On the basis of the results of separation experiments, a plant was designed to treat a plastic mixture of $\mathrm{PC} / \mathrm{PS} / \mathrm{ABS}=9 / 0.5 / 0.5$. Preliminary economic analysis was carried out to check the feasibility of this project. Results of economic analysis showed that for $10,000 \mathrm{~kg} /$ day throughput a selling price of $\$ 0.12 / \mathrm{lb}$ is required to breakeven. This result showed that it is promising to separate plastic mixtures with a solvent based process. 


\section{Recommendations}

Based on the experiments and results presented herein, the following recommendations for future work are made.

1. Obviously, a higher purity of recovered polymers can be obtained by using solvents to separate plastic mixtures. In this project, an average purity of $97.61 \%$ PC for all separation experiments represented a significant purification of PC. However, if purities greater than $98 \%$ are desired, a further separation stage is recommended to enhance the purity of recovered polymers. Such experiment was just performed but was not presented in this work. However, the results showed a higher purity could be obtained. So further stages of separation with solvents is worth checking.

2. A drying process exists in almost all separation technologies. Comparing with other technologies, one of advantages of this technology with solvents is that the drying time is short since the solvents used are very volatile, and so energy used for drying is saved. But on the other hand, the solvent loss could be big. How to prevent or reduce solvent loss is still a big issue in future work.

3. In this work, polymers dissolved in solvents were precipitated out by adding antisolvents because it is easier to operate in lab. But evaporating solvents to precipitate polymers is strongly recommended since the solvents used are so volatile. The benefits of such method are that equipment cost is reduced and energy will be saved, thus the total manufacturing cost will be reduced significantly. 
4. Solvent recycling was not done in this work, the recommended recycling method in Chapter 3 needs to be verified, and material balance of solvents should be made, the loss of solvents in the whole process should also be checked in future work.

5. Solvents investigated in this work are very limited. Although cyclohexane and acetone were the best solvents found, the solubility of PS in cyclohexane is not as good as expected. A solvent that can dissolve more PS at room temperature should be researched.

6. Investigation of pervaporation equipment cost should be continued since a very coarse estimation was used in Chapter 5. Solvent loss should be taken into account in economic analysis. A continues separation process should be considered to save cost when the throughput is large. 


\section{References}

Alfrey, T. and Gurnee, E. F. Organic Polymers. 1973

Barton, A. F. M. Handbook of Solubility Parameters and Other Cohesion Parameters. Second printing, 1985

Biancaniello, J., Fisher, M. M., Headley, L. and Kingsbury, T., Setting the Record Straight: Busting Common Myths about Plastics from Recovered Consumer Electronics. American Plastics Council, GPEC2003

Billmeyer, F. W. Jr. Textbook of Polymer Science. Fourth printing, March, 1996

Chemical Market Reporter, published weekly by Schnell Publishing. Co., New York.

Hendrix, J., Massey, K.A., Whitham, E. and Bras, B., Technologies for the Identification, Separation and Recycling of Automotive Plastics. International Journal of Environmentally Conscious Design and Manufacturing, 6, 2, pp. 37- 50, 1997

http://www.matche.com/EquipCost/Dryer.htm

Hwang, J.Y., Separation of Normally Hydrophobic Plastic Materials by Froth Floatation. US Patent 5,377,844, 1995

Jody, B.; Daniels, E. and Brockmeier, N. Recovering Car Plastics. CHEMTECH, pp. 41-44, November, 1994

Kubat, J.; Hedman, K. B.; Albihn, P. L. Recovery of Polystyrene Using Liquid Sulfur Dioxide. US Patent 4, 196, 105, Apr. 1, 1980

Kumasaka, S.; Tada, S.; Horikoshi, S.; Kamanaka, T.; Taniguchi, H. Process for Regenerating Resin. US Patent 4, 517, 312, May 14, 1985 
Leidner, J., Plastic waste: Recovery of Economic Value, pp. 106-108, Marcel Dekker, 1981

McCabe, W. L., Smith, J. C. and Harriott, P., Unit Operations of Chemical Engineering, $5^{\text {th }}$ Ed., McGraw-Hill, New York, 1993

Mizumoto, Y.; Hasegawa, S. Method for Treating Waste High-polymer Mixture. US Patent 4, 031, 039, Jun. 21, 1977

Moore, L. A. Reclaimer Apparatus. US patent 5, 300, 267, Apr. 5,1994

Perry, R. H., and Green, D., Perry's Chemical Engineer's Handbook, $6^{\text {th }}$ Ed., McGraw-Hill, New York,1984

Pomykala, J. A., Jody, B. J., Daniels, E. J. and Greminger, J. L., Separation and Recovery of Thermoplastics from Mixed-scrap Plastics. Global plastics environmental conference, Feb.26-27, Detroit, MI, 2003

Recovery of Plastics from Municipally Collected Electrical and Electronics Goods, MBA Polymers, Inc., A report sponsored by The Materials for the Future Foundation, Mar.1999

Sishir, D.G., Coal Upgrading Under Mild Conditions Using Supersolvents, MS Thesis, West Virginia University, 1990

Stessel, R. I., Pelz, S., Air Classification of Mixed Plastics. Proceedings of the 1994 National Waste Processing Conference, Boston, Massachusetts, June 5-8, American Society of Mechanical Engineers, pp. 333-339,1994

Super, M. S., Enick, R. M. and Beckman, E. J., Density-Based Separation of Thermoplastics in the Post-Consumer Waste Stream. Resources, Conservation, and Recycling, 9, pp.75-88, 1993

Turton, R., Bailie, R. C., Whiting, W.B., and Shaeiwitz, J.A., Analysis, Synthesis, and Design of Chemical Process. $2^{\text {nd }}$ Ed., Prentice Hall, 2002 
Vasudevan, V., Evaluation of the Separation Involved in Recycling End-of-Life (EOL) Electronic Equipment, MS Thesis, West Virginia University, 2003

Vestolit, M. J. and Solvay, J. Y. Recovery of Plastics Using Solvents. www.plasticsin-elv.org, 2002

Walas, S. M., Chemical Process Equipment: Selection and Design. Chapter 18 and 20, Butterworths, Boston, 1988

Walsh, W. C. Reclamation of Polymer That Contain Styrene in the Polymeric Backbone, Using Water Soluble Solvent Based Reclamation Process. US Patent 5, 594, 035, Jan. 14, 1997

Xiao, C.; Allen, L., Biddle, M. B., Fisher, M. M., Electronic Separation and Recovery of Mixed Plastics. American Plastics Council. Detroit, MI, November 1999

Yaws, C. L., Chemical properties handbook. McGraw-Hill, New York, 1999

Zhou, M., Persin, M., Kujawski, W. and Sarrazin, J., Electrochemical preparation of polypyrrole membranes and their application in ethanol-cyclohexane separation by pervaporation. Journal of Membrane Science, 108, pp.89-96, 1995 


\section{Nomenclature}

\section{Symbols}

$A \quad$ Heat exchange area $\left(\mathrm{m}^{2}\right)$; oxygen percent in recovered polymer in equation 3.1; Regression coefficients in equation 4.1

$B \quad$ Flow rate of bottom products ( $\mathrm{mol} / \mathrm{hr}$ ); Regression coefficients in equation 4.1

$C \quad$ Cost $(\$ / y r)$; Regression coefficients in equation 4.1

$C_{O L} \quad$ Cost of operating labor $(\$ / y r)$

COM Cost of manufacturing (\$/yr)

$C_{p, i} \quad$ Purchased cost for the major equipment units $(\$ / \mathrm{yr})$

$C_{R W} \quad$ Raw material cost (\$)

$C_{T M} \quad$ Capital cost $(\$)$

$C_{U T} \quad$ Utilities $(\$ / y r)$

$C_{W T} \quad$ Cost of waste treatment (\$/yr)

D $\quad$ Flow rate of overhead product (mol/hr); Regression coefficients in equation 4.1

$D_{c} \quad$ Diameter of column (m)

E Regression coefficients in equation 4.1

F $\quad$ Feed rate $(\mathrm{mol} / \mathrm{hr})$

$F_{\text {lang }} \quad$ Lang factor

$u \quad$ Heat transfer coefficient $\left(W / \mathrm{m}^{2} \cdot{ }^{\circ} \mathrm{C}\right)$

$K_{v} \quad$ Empirical coefficient

$L \quad$ Flow rate of liquid in rectifying column ( $\mathrm{mol} / \mathrm{hr}$ )

$\overline{\mathrm{L}} \quad$ Flow rate of liquid in stripping column ( $\mathrm{mol} / \mathrm{hr}$ )

$M \quad$ Mass flow rate $(\mathrm{kg} / \mathrm{day}, \mathrm{kg} / \mathrm{hr})$

$\mathrm{n} \quad$ Total number of individual units

$\mathrm{N} \quad$ Number of trays

$N_{n p} \quad$ Number of equipment

$N_{o l} \quad$ Number of operators

$\mathrm{P} \quad$ Vapor pressure; the process steps in equation 5.61

$R \quad$ Reflux ratio

$R_{\min } \quad$ Minimum reflux ratio 


$\begin{array}{ll}q & \text { Moles of liquid to stripping section of column per mole of feed } \\ \mathrm{T} & \text { Temperature }\left({ }^{\circ} \mathrm{C}\right) \\ \mathrm{U}_{\mathrm{c}} & \text { Maximum permissible velocity based on bubbling area }\left(\mathrm{m}^{2}\right) \\ V & \text { Volume (gallon); flow rate of vapor in rectifying column }(\mathrm{mol} / \mathrm{hr}) \\ \overline{\mathrm{V}} & \text { Flow rate of vapor in stripping column }(\mathrm{mol} / \mathrm{hr}) \\ \mathrm{X} & \text { Purity of PC } \\ X_{b} & \text { Mole fraction in bottom product } \\ X_{d} & \text { Mole fraction in overhead product } \\ X_{f} & \text { Mole fraction in feed } \\ Y & \text { Mole fraction in vapor } \\ \rho_{\mathrm{L}} & \text { Density of liquid }\left(\mathrm{kg} / \mathrm{m}^{3}\right) \\ \rho_{\mathrm{V}} & \text { Density of vapor }\left(\mathrm{kg} / \mathrm{m}^{3}\right) \\ \lambda & \text { Latent heat of vaporization }(\mathrm{cal} / \mathrm{g})\end{array}$

\section{Abbreviations}

ABS Acrylonitrile butadiene styrene

EA Elemental analyzer

EOL End-of- life

ESR Electronic shredder residue

FT-IR Fourier transform infrared spectroscope

HDPE High density polyethylene

HIPS High impact polystyrene

MIBC Methyl isobinol carbinol

MOC Materials of construction

NMP N-methyl pyrrolidone

LDPE Low density polyethylene

PC Polycarbonate

PET Polyethylene terephthalate

PP Polypropylene

PS Polystyrene

PVC Polyvinylchloride 